\title{
Governing Knowledge Commons
}

Edited by

Brett M. Frischmann

Michael J. Madison

Katherine J. Strandburg 


\title{
Contents
}

\author{
Introduction ix
}

I. Governing Knowledge Commons/by Brett M. Frischmann, Michael J. Madison, and Katherine J. Strandburg I

2. Learning from Lin: Lessons and Cautions from the Natural Commons for the Knowledge Commons/by Daniel H. Cole 45

3. Between Spanish Huertas and the Open Road: A Tale of Two Commons?/by Yochai Benkler 69

4. Constructing the Genome Commons/by Jorge L. Contreras 99

4B. Governing Genomic Data: Plea for an "Open Commons”/by Geertrui Van

Overwalle 137

5. The Rare Diseases Clinical Research Network and the Urea Cycle Disorders

Consortium as Nested Knowledge Commons/by Katherine J. Strandburg, Brett

M. Frischmann, and Can Cui I5s

6. Commons at the Intersection of Peer Production, Citizen Science, and Big Data: Galaxy Zoo/by Michael J. Madison 209

7. Toward the Comparison of Open Source Commons Institutions/by Charles

M. Schweik 255

8. Governance of Online Creation Communities for the Building of Digital

Commons: Viewed through the Framework of Institutional Analysis and Development/

by Mayo Fuster Morell 28I

9. Creating a Context for Entrepreneurship: Examining How Users' Technological and Organizational Innovations Set the Stage for Entrepreneurial Activity/by Sonali K. Shah and Cyrus C. M. Mody 313 
viii Contents

10. An Inventive Commons: Shared Sources of the Airplane and Its Industry/by Peter

B. Meyer 34I

II. Exchange Practices among Nineteenth-Century U.S. Newspaper Editors: Cooperation in Competition/by Laura J. Murray 365

12. How War Creates Commons: General McNaughton and the National Research

Council, 1914-1939/by S. Tina Piper 391

13. Labor and/as Love: Exploring the Commons of Roller Derby/by

David Fagundes 417

14. Legispedia/by Brigham Daniels 445

I5. Conclusion/by Brett M. Frischmann, Michael J. Madison, and Katherine J. Strandburg 469

INDEX 485 


\title{
Introduction
}

\author{
Brett M. Frischmann, Michael J. Madison, and Katherine J. Strandburg*
}

The economics of the new commons is still in its infancy. It is too soon to be confident about its hypotheses. But it may yet prove a useful way of thinking about problems, such as managing the internet, intellectual property or international pollution, on which policymakers need all the help they can get. ${ }^{1}$

This book seeks to contribute to evidence-based policy making about innovation and creative production. Critics rightly complain that anecdote, ideology, wishful thinking, and brute political influence, more than empirical understanding, often drive intellectual property policy making. We are concerned that recent enthusiasm about knowledge commons approaches (which we share) may be open to the same critique. Rather than embracing knowledge commons indiscriminately, policy making should be based on more evidence and deeper understanding of what makes them tick.

We embrace the analogy between the cultural environment and the natural environment (Boyle 2008; Frischmann 2007) in order to explore the proposition that just as natural resources often are governed by commons, rather than being managed as either public or private property, the production and sharing of knowledge often is sustained by commons governance. Scholars of the natural environment have developed successful methods for

\footnotetext{
* Brett M. Frischmann is Professor of Law and Director of the Intellectual Property and Information Law Program at the Benjamin N. Cardozo School of Law, Yeshiva University, New York, New York, USA. Michael J. Madison is Professor of Law and Faculty Director of the Innovation Practice Institute at the University of Pittsburgh School of Law, Pittsburgh, Pennsylvania, USA. Katherine J. Strandburg is the Alfred B. Engelberg Professor of Law and a Faculty Director of the Engelberg Center for Innovation Law and Policy at the New York University School of Law, New York, New York, USA. Each is also a member of the Affiliated Faculty of the Vincent and Elinor Ostrom Workshop in Political Theory and Policy Analysis.

${ }^{1}$ Commons Sense, The economist (July 31, 2008), at 76, http://www.economist.com/node/1i848182.
} 
studying commons arrangements systematically and in detail. We borrow from them and propose a framework for studying knowledge commons that begins with the Institutional Analysis and Development (IAD) framework developed and used by Elinor Ostrom and others and adapts it to the unique attributes of knowledge and information.

This book describes the framework, in Chapter I and then includes case studies, reactions, and comments from a group of interdisciplinary researchers. The purpose of this book is to begin the careful, detailed exploration of how knowledge commons function, the place they occupy in the cultural environment, the specific benefits they offer, the costs and risks they create, and their relationships to other institutional structures. Eleven case studies of knowledge commons are at the heart of book. The case study authors come from many different research traditions. The cases vary across a broad range of cultural and scientific domains and historical and contemporary practice. This volume brings these studies together as an initial demonstration of the value of studying knowledge commons carefully, in a comparative fashion, in order to develop evidence of the details of their purposes and operations. We hope that in time, empirical study of knowledge commons will show that, properly understood, they may be harnessed and even designed for broad public benefit Our concluding chapter highlights the framework's success in bringing forward commonalities and differences between knowledge commons, while recognizing that producing generalizable understanding will require many more studies.

As law professors, we undertook this project initially out of interest in the functioning of systems of intellectual property rights - patent, copyright, and related bodies of law. Whether we look at the economics of the global knowledge economy or at the potential for collaboration and innovation unleashed by the computer and network revolutions of the last thirty years, the impulse to examine innovation institutions and behaviors is immediate. Wikipedia is a fascinating thing. The questions that it raises include not only "why do people contribute to Wikipedia?" but also "in cultural, economic, and legal terms, how does Wikipedia function today and how will it evolve in the future?" Linux is a widely used and commercially successful example of an open source computer program. Why have it and other open source programs succeeded, institutionally and organizationally? Why have some open source computer programs not thrived? Similarly broad questions can and should be directed to collaborative enterprises in science, technology, the arts, government, and beyond.

Traditionally, when intellectual property law scholarship examined institutions for promoting innovation and creativity, it divided the world into two, default perspectives: innovation systems organized around markets, supported by intellectual property rights directed to exclusivity and ownership, and innovation systems organized around governments, which intervene in markets (or avoid markets) in various ways to sponsor and subsidize innovation. A third approach, commons-based sharing of knowledge and information resources to produce innovation and creativity, is increasingly acknowledged and celebrated, as suggested by the article in The Economist magazine quoted above. But writing about the commons approach is often conceptual or 
political, using the idea of commons as a rhetorical device to oppose the expansion of intellectual property protection (Boyle 2008; Hyde 2010). Empirical study of normand custom-based innovation communities often is developed in opposition to (and therefore in reliance on) market-based presumptions of the need for exclusivity, substituting norm-based exclusivity for legal-defined intellectual property (Raustiala \& Sprigman 2012).

One of our goals here is to stake out knowledge commons as an independent, affirmative means for producing innovation and creativity and an important domain for research. In our view, commons are neither wholly independent of nor opposed to markets based on exclusive rights (whether formal or informal), nor are they subordinate to them.

As noted, our approach is inspired by the pathbreaking research of the late Elinor Ostrom, who was awarded the Nobel Prize in Economic Sciences in 2009 for her lifetime of research into the functioning of commons governance, especially in the natural resources context. Ostrom was far from the first scholar to examine resource systems and governance using tools of comparative institutional analysis. But her work and that of her collaborators and successors highlighted commons as an object of study in a way that no scholar had done before. Ostrom also approached the topic with an extraordinary humility and disciplinary generosity, recognizing that understanding this complex area could only be achieved through the contributions of researchers from many fields, aligned via shared methods. Her impact was magnified by her emphasis on a shared research framework accessible to and usable by numerous disciplines. We have tried to extend both the spirit and style of Ostrom's work to our own.

Toward the end of Ostrom's career, she and her colleagues recognized the emerging importance of knowledge commons as an area for sustained research and began to apply the IAD framework to them (Ostrom \& Hess 2007; Hess 2012). In 2010 we developed a research framework specifically tailored to the properties that distinguish knowledge and information from natural resources (Madison, Frischmann, \& Strandburg 2010). That framework, with some elaborations and clarifications, follows this introduction as Chapter I of this book.

The balance of the book is organized as follows.

Chapter I lays out our research framework in detail, including its origins in Ostrom's work on commons, the background assumptions of scholarship on intellectual property rights and theories, and the template for organizing research inquiries in particular case studies. It explains in more detail what we mean by knowledge commons, why knowledge commons deserve systematic study, and why we were motivated to write this book. Chapter i provides a thorough explanation of our proposed framework that we hope will encourage and enable others to use and improve upon it in their own studies of knowledge commons.

Chapters 2 and 3 situate the study of knowledge commons within a broader context. In Chapter 2, Dan Cole relates the knowledge commons project to Elinor Ostrom's work on natural resource commons, illustrating points of continuity and points of distinction. 
Cole offers encouragement and caution to scholars seeking to use Ostrom's work as a starting point for studying knowledge commons. He encourages those seeking "conceptual, analytical, and methodological guidance," arguing that Ostrom's work can provide a foundation for "improv[ing] understanding of information and information flows under alternative institutional arrangements," "diagnos[ing] problems in existing institutional arrangements," and even "predict[ing] outcomes under alternative institutional arrangements." He cautions, however, that those looking to Ostrom's work for normative guidance as to the proper structure of intellectual property law are "bound to be disappointed (or dishonest)" for two reasons: First, Ostrom's work teaches that there are "no panaceas." Second, researchers necessarily choose metrics for assessing commons outcomes. Whereas long-run sustainability is a widely accepted goal for natural resource commons, Cole suggests that outcome metrics for knowledge commons are likely to be much more contested.

In Chapter 3, Yochai Benkler provides a conceptual map for understanding the range of different types of commons that are important to society and deserve systematic study. He argues that there are important differences between the institutional arrangements studied by Ostrom and colleagues, in which a "defined set of claimants" share resources in a self-governing arrangement, and public domain or open access commons, which provide "freedom-to-operate under symmetric constraints, available to an open, or undefined, class of users." Benkler reminds us that knowledge commons arrangements are layered on top of and dependent upon substantial resource sets governed either as public domain commons or through private property arrangements.

Chapters 4, 5, and 6 apply the knowledge commons research framework to commons arrangements for scientific research, where tradition and custom teach that formal intellectual property rights are particularly unlikely to play key roles in institutional governance, but where the knowledge commons research framework nonetheless reveals meaningful structure and governance of knowledge sharing. In Chapter 4, Jorge Contreras targets the genomics research collaborative that constituted the Human Genome Project. Geertrui Van Overwalle follows that chapter with a comment that notes the global context of research on genomic commons, illustrating that commons in general have important international and comparative dimensions. In Chapter 5, Katherine Strandburg, Brett Frischmann, and Can Cui delve into a network of medical researchers and patient advocacy groups titled the Rare Diseases Clinical Research Network, and the related Urea Cycle Disorders Consortium. In Chapter 6, Michael Madison describes a citizen science project, called Galaxy Zoo, that pairs professional astronomers with amateurs.

Chapters 7 and 8 involve commons cases situated in the context of information and communications technologies (sometimes abbreviated ICTs). In Chapter 7, Charles Schweik presents the results of a comparative analysis of open source software development communities. In Chapter 8, Mayo Fuster Morell reports a study of online creation communities (OCCs) such as the photosharing site, Flickr, used for sharing creative content supplied by individuals. 
Chapters 9, I0, and II involve commons cases that highlight the role of commons governance as it intersects with or overlaps with other governance institutions directed to knowledge production. In Chapter 9, Sonali Shah and Cyrus Mody describe entrepreneurship, and particularly entrepreneurship by technology users, using the knowledge commons perspective and borrowing examples from such diverse domains as windsurfing and probe microscopy. In Chapter ıo, Peter Meyer reviews the history of the development of the fixed-wing airplane as an industrial invention, and its associated industries, as the product of open innovation communities that operated in the shadow of patent law. In Chapter in, Laura Murray describes the history of newspapers with specific attention to historical norms that balanced proprietary control and sharing in journalism.

Chapters I2, I3, and I4 push the knowledge commons research framework in directions that illustrate its utility in contexts far from those the term immediately brings to mind. In Chapter I2, S. Tina Piper studies the history collaborative invention communities in the Canadian military. In Chapter 13, David Fagundes delves into the world of roller derby, an amateur sporting community that is governed almost entirely by informal norms. In Chapter i4, Brigham Daniels subjects the U.S. Congress to study as a case of commons governance in its production of legislation.

As the conclusion to this book points out in greater detail, the first and perhaps most important takeaway from this book is borrowed from a line sometimes attributed to Mark Twain. Asked if he believed in infant baptism, Twain allegedly replied, "Believe it? I've seen it done!" And so with the study of knowledge commons. An impressive collection of extremely thoughtful scholars has dissected a broad range of cases of commons in ways that usefully illuminate the workings of each case and, even more important, set the stage for continued comparative analysis of their results. The power and future of commons lies not just in the politics and rhetoric of commons but also in empirical understanding of when and how knowledge commons governance work-and when it doesn't.

We conclude this introduction by pointing out that our collaboration in producing this work, and in collaborating with the other contributors, is itself best described as a knowledge commons. None of this research would be possible without extraordinary sharing of time, expertise, interest, and ideas. The future of this project depends on continuing that collaboration and expanding it. We hope that reading it inspires you to consider giving our framework a try and encourage you to reach out to us with your ideas and insights for follow-on work.

\section{Acknowledgments}

The collaboration that underlies this book began in conversations among the editors about cultural commons and knowledge commons in 2006 and 2007. It took root with the publication of Madison, Frischmann, \& Strandburg (2010) and with responses to 
that article from a group of generous scholars (Ostrom 2010; Merges 2010; Gordon 2010; Solum 2010; Macey 2010; Eggertson 2010). It continued in September 2011 as a number of researchers from around the world gathered at the Engelberg Center for Innovation Law and Policy at New York University School of Law for a workshop titled "Convening Cultural Commons." Many of the chapters in this volume were shared in early form in that setting. As editors of this volume and participants in an emerging global enterprise for the study of knowledge commons, we are grateful for the openness with which the work has been received so far and look forward to more and continuing discussion of this important topic.

Professor Strandburg acknowledges the generous support of the Filomen D'Agostino and Max E. Greenberg Research Fund.

\section{References}

James Boyle, The Public Domain: Enclosing the Commons of the Mind (Yale University Press 2008)

Commons Sense, The Economist (July 31, 2008), at 76, http://www.economist.com/node/ II 848 I 82 .

Thráinn Eggertsson, Response: Mapping Social Technologies in the Cultural Commons, 95 Cornell L. Rev. 7 II (2010).

Brett M. Frischmann, Cultural Environmentalism and the Wealth of Networks, 74 U. CHI. L. Rev. 1083 (2007).

Wendy J. Gordon, Response: Discipline and Nourish: On Constructing Commons, 95 CornelL L. REv. 733 (2010).

Charlotte Hess, Constructing a New Research Agenda for Cultural Commons, in Cultural Commons: A New Perspective on the Production and Evolution of Cultures I9 (Enrico Bertacchini et al. eds., Edward Elgar Publishing 20I2).

Lewis Hyde, Common as Air: Revolution, Art, and Ownership (Farrar, Straus and Giroux 20IO).

Gregg P. Macey, Response: Cooperative Institutions in Cultural Commons, 95 CoRnell L. Rev. 757 (2010).

Michael J. Madison, Brett M. Frischmann, \& Katherine J. Strandburg, Constructing Commons in the Cultural Environment, 95 CORNell L. Rev. 657 (2010).

Robert P. Merges, Response: Individual Creators in the Cultural Commons, 95 Cornell L. Rev. 793 (2010).

Elinor Ostrom, Response: The Institutional Analysis and Development Framework and the Commons, 95 Cornell L. Rev. 807 (2010).

Elinor Ostrom \& Charlotte Hess, A Framework for Analyzing the Knowledge Commons, in Understanding Knowledge as a Commons: From Theory to Practice (Charlotte Hess \& Elinor Ostrom eds., MIT Press 2007).

Kal Raustiala \& Christopher Sprigman, The Knockoff Economy: How Imitation Sparks InNovation (Oxford University Press 2012).

Lawrence B. Solum, Response: Questioning Cultural Commons, 95 Cornell L. Rev. 817 (2010). 


\section{Governing Knowledge Commons Brett M. Frischmann, Michael J. Madison, and \\ Katherine J. Strandburg*}

\section{Introduction}

This chapter sets out the knowledge commons framework that forms the foundation for the case study chapters that follow (Madison, Frischmann, \& Strandburg 20IOa). The framework builds on the Institutional Analysis and Development (IAD) approach pioneered by Elinor Ostrom and her collaborators for studying commons arrangements in the natural environment (Ostrom 1990). By "knowledge commons" we refer broadly to commons arrangements for overcoming various social dilemmas associated with sharing and producing information, innovation, and creative works (Ostrom \& Hess 2006). ${ }^{1}$ This

\footnotetext{
* Brett M. Frischmann is Professor of Law and Director of the Intellectual Property and Information Law Program at the Benjamin N. Cardozo School of Law, Yeshiva University, New York, New York, USA. Michael J. Madison is Professor of Law and Faculty Director of the Innovation Practice Institute at the University of Pittsburgh School of Law, Pittsburgh, Pennsylvania, USA. Katherine J. Strandburg is the Alfred B. Engelberg Professor of Law and a Faculty Director of the Engelberg Center for Innovation Law and Policy at the New York University School of Law, New York, New York, USA. Each is also a member of the Affiliated Faculty of the Vincent and Elinor Ostrom Workshop in Political Theory and Policy Analysis.

${ }^{1}$ In the paper on which this chapter is based (Madison, Frischmann, \& Strandburg 20Ioa), we referred to these as cultural commons, which we treat as equivalent to knowledge commons, and as constructed cultural commons. Cultural commons has been used recently by some other commons scholars (Enrico Bertacchini et al. 2012; Hess 2012). Our approach is inclusive of theirs but perhaps broader. The term "constructed" refers to the idea, which we address in more detail below, that the resources in knowledge commons are built by human agency, rather than found somehow in nature.
} 
book includes case studies of a number of knowledge commons arrangements involving the creation and sharing of a diverse array of knowledge resources, such as scientific data, open source software, news resources for journalism, technological innovations, online knowledge resources such as Wikipedia, congressional legislation, and information used by roller derby participants. Some further examples of the types of arrangements we have in mind are patent pools (such as the Manufacturers Aircraft Association), the Associated Press, certain jamband communities, medieval guilds, and modern research universities. These examples are illustrative and far from exhaustive.

The systematic approach to case study design and analysis provided by the knowledge commons framework is intended not only to structure individual case studies in a useful and productive way but also to make it possible eventually to produce generalizable results. By comparing and aggregating case studies performed according to the knowledge commons framework, it should be possible to inventory the structural similarities and differences between commons in different industries, disciplines, and knowledge domains and to shed light on the underlying contextual reasons for the differences. This structured inquiry will provide a basis for developing theories to explain the emergence, form, and stability of the observed variety of knowledge commons and, eventually, for designing models to explicate and inform institutional design. In addition, an improved understanding of knowledge commons is critical for obtaining a more complete perspective on intellectual property (IP) doctrine and its interactions with other legal and social mechanisms for governing creativity and innovation.

WHAT DO WE MEAN BY KNOWLEDGE COMMONS?

"Knowledge commons" is shorthand. It refers to an approach (commons) to governing the management or production of a particular type of resource (knowledge).

Commons refers to a form of community management or governance. It applies to resources, and involves a group or community of people, but commons does not denote the resources, the community, a place, or a thing. Commons is the institutional arrangement of these elements. "The basic characteristic that distinguishes commons from noncommons is institutionalized sharing of resources among members of a community" (Madison, Frischmann, \& Strandburg zorob: 84I). Critically, commons governance is used by a wide variety of communities to manage many different types of resources. Commons governance confronts various obstacles to sustainable sharing and cooperation. Some of those obstacles derive from the nature of the resources and others derive from other factors, such as the nature of the community or external influences. Communities can and often do overcome obstacles through constructed as well as emergent commons.

Knowledge refers to a broad set of intellectual and cultural resources. In prior work, we used the term "cultural environment" to invoke the various cultural, intellectual, 
scientific, and social resources (and resource systems) that we inherit, use, experience, interact with, change, and pass on to future generations. We used this terminology to convey the broad range of resources we had in mind but have since realized that some readers found it confusing. Here we use the term "knowledge." We emphasize that we cast a wide net and that we group information, science, knowledge, creative works, data, and so on together.

Knowledge commons is thus shorthand for the institutionalized community governance of the sharing and, in some cases, creation, of information, science, knowledge, data, and other types of intellectual and cultural resources.

Some initial illustrations of knowledge commons suggest the variety of institutional arrangements we believe may be usefully studied using the framework described here.

Intellectual property pools. A patent pool is an agreement by two or more patent holders to aggregate and share their patents by cross-licensing (Shapiro 2000). The patents in question typically relate to complementary technologies, where one holder's exercise of patent rights "blocks" a different holder's exercise of related rights. Pooled patents are typically available to all members of the pool and are available to nonmembers on standard licensing terms. A well-known example of an early patent pool in the United States is the Manufacturers Aircraft Association (MAA), which formed in 1917 and encompassed nearly all American aircraft manufacturers. The Wright Company and Curtiss Company held major patents on aircraft technology, but Wright and Curtiss did not hold all relevant patents, and for any given manufacturer, the cost of licensing a single needed patent from a competitor might have made manufacturing an airplane prohibitively expensive. During World War I, the U.S. government needed airplanes at reasonable costs and in a short time. As a result, the government facilitated the implementation of the MAA, a private corporation. The MAA entered into an agreement with airplane manufacturers, through which the manufacturers pooled their patents and their potential claims for exploitation of the patents by rivals and agreed to cross-licensing of the patents to one another on what was, essentially, a royalty-free basis (Dykman 1964; Merges 1996: 1343-46). Largely because of this functioning commons of patented inventions, airplanes were built.

Open source software. The Linux operating system, an alternative to Windows and Mac OS (the Macintosh operating system), was produced and is still maintained by a collaborative of individual programmers, many of whom are volunteers (some are employed in firms, some of which produce and/or support commercial versions of the Linux software). The Linux collaborative is linked loosely by communications technologies, by members' voluntary allegiance to the project, and by the terms of an open source license. Unlike proprietary computer programs, which are distributed to users in object code or executable format only, open source programs such as Linux are made available in source code form so that members of the community may modify their copies and, under the terms of the governing license, publish their modifications for use by others. Members of the 
community may also volunteer their modifications for inclusion in the standard Linux code base. Each member of the Linux community may use material in the Linux commons and may contribute material back to the Linux commons. Each individual member of the community contributes code to the accumulated archive of the Linux kernel, which is the core of the operating system. The rules governing the use of open source material and contributions to the open source commons are partly formal and partly informal. Formally, the software is governed by copyright law, and its use is managed by the terms of the General Public License. Informally, the integrity of Linux as an identifiable and stable program depends on a thin hierarchy of informal authority, which extends from Linus Torvalds at the top to the body of individual developers at the bottom. The result is an exemplary version of a successful open source software program: a complete, complex, and successful industrial product that is built and maintained not by a traditional, hierarchical, industrial firm, but by a loose-knit community (Kelty 2008; Schweik \& English 20I2).

Wikipedia. This free, online encyclopedia is widely read and cited. It resembles an open source software project in many respects. Volunteer authors create and edit Wikipedia entries; anyone with Internet access can read and use the contents of Wikipedia. Wikipedia is not the product of unregulated, potentially chaotic, openness. A governance structure exists among "Wikipedians" that modulates the openness of the project and operates as a kind of law (Hoffman \& Mehra 2009). For example, not all additions and edits to Wikipedia are automatically added to the site. Moreover, a Creative Commons Attribution-ShareAlike license, the copyright license that governs the contents of Wikipedia, restricts the use of the contents of the site. ${ }^{2}$ Wikipedia also has a dispute-resolution system that plays an important role in sustaining the commons. The site is open, but with limits.

The Associated Press. For more than a century, the Associated Press (AP) has been the leading American wire service for newspapers (Reporters of the Associated Press 2007). It offers a compelling example of a knowledge commons that is not grounded in formal IP rights. As factual material, the news itself cannot be copyrighted (though there is an important but narrow "hot news misappropriation" tort rule (Gordon 2009: 242I-23)). Local newspapers could not afford to cover all of the stories that their readers wanted to read, yet the ease with which news stories can be appropriated served as a disincentive to invest in reporting - a classic free-rider dilemma. The solution was a not-for-profit cooperative, owned by the participant news organizations, which partnered originally with Western Union (Shmanske i986). Cooperative members could both upload material that they originated locally to the wire service and download material that other members produced from the wire service. Local papers were able to carry AP reports on national and international news that they otherwise could not have afforded to produce. Without discounting allegations that the AP's content was biased politically and that it behaved

\footnotetext{
${ }^{2}$ See Wikipedia: Licensing update, at http://en.wikipedia.org/wiki/Wikipedia:Licensing_update.
} 
monopolistically, considerations that highlight the need to view commons with a critical eye, the AP itself operated as a structured commons managed by its members.

Jamband fan communities. Musical groups known as jambands "jam," or improvise heavily, during live performances. Beginning with fans of the best-known jamband, the Grateful Dead, jamband fan communities have long been encouraged by the artists themselves to produce and share their own concert recordings. These recordings initially were shared via physical media and now are shared using online archives (organized via the website and organization etree.org). The bands encourage this sharing, provided that the fans comply with informal rules that are set by the bands and honored and policed by the fan communities themselves (Schultz 2006). For example, as Schultz describes in his detailed case study of the jamband phenomenon, fan communities generally undertake not to interfere with commercial exploitation of the bands' own concert recordings (Schultz 2006, 675-76). Commons governance of jamband recordings is structured not merely by fan expectations that norms will be honored but also by file sharing and archiving technologies that reinforce the commercial/noncommercial distinction, by intermediary institutions that host jamband archives, and by the bands, which cooperate with and nurture their fan communities (Schultz 2006: 679-80).

At first glance, these examples may appear to be disparate and unrelated. Yet we believe that a systematic, comprehensive, and theoretically informed research framework offers significant potential to produce generalizable insights into these commons phenomena. Comparative institutional investigation of knowledge commons is relevant to our understanding of social ordering and institutional governance generally. It should also produce insights important to intellectual property law. The conventional view of intellectual property is that resource production and consumption are (and ought to be) characterized primarily by entitlements to individual resource units, held individually and allocated via market mechanisms (Merges 1996: 4-7). To the extent that those market mechanisms are inadequate to optimize the welfare of society, or, in other words, in the event of market failure, government intervention may be appropriate. Intellectual property rights traditionally are justified on precisely this basis (Lemley 2005: 1073). Creative works and new inventions are characterized as public goods, whose intangibility prevents their originators from excluding potential users and thus recouping their investments via sales (Lemley 2005: 1050-55). Copyright and patent laws create artificial but legally sanctioned forms of exclusion, restoring a measure of market control to creators and innovators. Where propertization is insufficient, government subsidy is seen as the primary alternative. Communal and collectivist institutions, particularly those that blend informal normative structures with formal governance rules, are generally regarded as exceptional and dependent upon preexisting property entitlements (Rose 2008: 432-28).

The research framework that we describe below offers a method for assessing the validity of this property-focused narrative. We anticipate that study of a large number of cases 
using the framework, ranging broadly across different knowledge and cultural contexts, is likely to demonstrate that successful knowledge production and management occurs within a wide variety of formal and informal institutional arrangements. We suspect that the logical and normative priority assigned to proprietary rights and government intervention will turn out to be misplaced.

\section{The Backdrop: Intellectual Property, Free Riding, Commons, and the Need for Empirical Study of Knowledge Commons}

This part begins with a brief discussion of the free-rider allegory that provides the traditional foundation for intellectual property law and theory. It describes the limitations of the free-rider paradigm and of intellectual property as a panacean approach to knowledge production. It then notes the rise of community production as an alternative model for knowledge production and expresses concern that, in some circles, community production may be emerging as an alternative panacean approach. It argues that policy and theory aimed at resolving the complex issue of how best to produce and manage intellectual resources should be grounded in a more detailed and nuanced empirical understanding.

\section{A. FUNCTIONALIST INTELLECTUAL PROPERTY THEORY AND ITS LIMITS}

Intellectual property law scholarship typically has viewed invention, creative expression, innovation, and related or subsidiary activities (such as research and development) as a special set of practices for which extra encouragement is warranted. Despite considerable variation and nuance, these activities all can be understood to present the same core problem. The "outputs" from these activities-whether described as information, expression, invention, innovation, research, ideas, or otherwise-are public goods. They are naturally nonrivalrous or nondepletable, meaning that consumption of the good does not deplete the amount available to other users, and nonexcludable, meaning that knowledge outputs are not naturally defined by boundaries that permit cheap exclusion of users (Frischmann 2012: 24-30, 26I-68; Frischmann \& Lemley 2007: 272-273; Cornes \& Sandler 1996: 40-43). As a result, the production of such resources faces a well-known supply-side problem, common to public goods. The inability to (cheaply) exclude competitors and nonpaying consumers (often called "free riders") presents a risk to investors. This risk is perceivable ex ante (prior to production of the good) and thus may lead to undersupply. Essentially, in the absence of some institutional solution, there would be a significant underinvestment in (some types of) intellectual resources because of the risk that competitors would appropriate their value (Frischmann 2009a: 2156).

The extent of the free-rider problem in a given instance will depend on the costs of exclusion and boundary setting. But even if low-cost exclusion of free riders is feasible, the nonrivalry of intellectual resources means that markets still will tend to undersupply 
them. While exclusion enhances incentives to create some intellectual resources, it simultaneously limits their availability (Frischmann 2012: 26I-68). An additional layer of complexity emerges when we look beyond intellectual resources as isolated "goods" and consider their importance as inputs, outputs, and continuous constituents of complex intellectual, cultural, economic, and social processes and systems (Frischmann 2012:26875; Benkler 2006: 37). The conventional approach to intellectual property collapses this complexity into a linear conception of trade-offs or balancing between "upstream" and "downstream" creators.

At its core, the free-rider allegory illustrates the social dilemma associated with a standard externality problem-each individual free rider rationally maximizes his or her private welfare without accounting for external costs. In this context, the social costs encompass the risk to investment and resulting underproduction of public goods over time. The model easily can be mapped onto the classic collective action problem, in which unconstrained consumption appears unsustainable, producing the so-called "tragedy of the commons."

In remarkable parallelism with the history of the tragedy of the commons allegory and its role in environmental circles, many analysts of knowledge production issues simply assume the free-rider allegory describes a normal rather than exceptional problem. Also, in remarkable parallelism, a binary solution set, comparable to the standard set of solutions in physical resource production settings, seems to follow naturally: To avoid tragedy, society must turn to production subsidized by government or to markets enabled by property rights, specifically intellectual property rights. Both approaches rely on collective action through government, but they differ substantially in terms of the manner in which resource allocation decisions are made (Frischmann 2013). Government subsidization deals with the underproduction problem head on. Government allocates funds to selected research activities that yield intellectual resources, which can, in principle, be shared openly and freely within the "public domain."3 Intellectual property rights, such as patents and copyrights, address the underproduction problem by enabling markets to function more effectively in supplying intellectual resources. Intellectual property rights lower the costs of exclusion, enable transactions, and mitigate the risks to investment posed by free riders. Yet, for a variety of reasons that are beyond the scope of this introduction, both solutions are incomplete and entail a host of significant problems.

The free-rider allegory heavily influences the framing and perception of the institutional arrangement of the cultural environment, by dividing it into two conceptual domains. First, there is the domain of intellectual property, in which producers of creative and innovative things employ proprietary rights sanctioned by law to control development, distribution, and exploitation of intellectual resources. IP law constructs and assigns these exclusive rights and encourages their exploitation through market exchange.

\footnotetext{
${ }^{3}$ For various reasons that are beyond the scope of this discussion, government-subsidized knowledge resources are not always contributed to the public domain.
} 
Private rights and private market exchange serve to limit, by law, the natural shareability of knowledge and innovation. The intellectual property perspective assumes that producers would abandon their efforts to produce, develop, and/or disseminate knowledge goods for fear of free riding by competitors or consumers.

Second, there is the public domain, a vast collection of openly accessible knowledge resources. The purpose of maintaining a public domain is to permit any and all comers to appropriate its resources freely and to use them to create or innovate anew. For some resources, the benefits of overcoming the free-rider problem are outweighed by the social value of permitting the resources to serve as the foundation for new creations and innovations or otherwise to be used in ways that are socially beneficial, such as when fair uses of copyrighted expression support public capabilities associated with education or political participation. Some resources enter the public domain as the result of direct or indirect provisioning by government using a combination of grants to researchers; tax credits or subsidies to researchers and enterprises that employ them; prizes; and production and distribution of knowledge and innovation by the government itself, either by organizing research enterprises or by purchasing and distributing private research. Other resources occupy the public domain because of limitations to existing intellectual property systems (for example, due to express exclusion from the system as uncopyrightable ideas ${ }^{4}$ or unpatentable laws or products of nature, ${ }^{5}$ or to expiration of rights. ${ }^{6}$ ) These limitations attempt to balance free-rider concerns against the social costs of awarding exclusive rights to nonrivalrous resources. Sometimes resources effectively belong to the public domain despite being legally subject to intellectual property rights because those rights are not enforced (for example, because potential owners dedicate their resources to the public or because exclusion is practically impossible).

This conventional two-part framing is woefully inadequate as a descriptive matter. The traditional free-rider allegory provides little insight into determining how and whether particular intellectual resources should be, or are, supplied to the public domain. Essentially, both the allegory and the institutional framing to which it relates are caricatures-oversimplified accounts that roughly describe some cultural practices and productive activities but leave much too much out of frame, unexamined, and unaccounted for. Frischmann (2013) recently suggested that

we should ask two foundational sets of questions: First, how well does the free rider allegory describe reality? Is it a useful theory for making predictions about

\footnotetext{
${ }^{4}$ See, e.g., I7 U.S.C. $\$ \$$ 102, I07 (2012) (providing for limits on the scope of copyrightable subject matter and for the fair use defense).

${ }^{5}$ See, e.g., 35 U.S.C. $\$ 1$ IOI, 102, 103 (2012) (providing for limits on the scope of patentable subject matter); Diamond v. Chakrabarty, 447 U.S. 303,309 (1980) (noting that the laws of nature, physical phenomena, and abstract ideas are not patentable).

${ }^{6}$ See U.S. Const. Art. I, $\$ 8$, cl. 8 ("limited times"); 17 U.S.C. $\$ 302$ (2012) (establishing the duration of a copyright); 35 U.S.C. $\$ 154(\mathrm{a})(2)$ (2012) (establishing the duration of a patent).
} 
real-world behavior of individuals? Does it describe a normal or exceptional situation? Does it provide a useful basis for choosing or designing regulatory solutions? Second, does the binary choice between government subsidization and intellectual property-enabled markets reflect the full range of options? Are there alternative institutions and/or means for collective action?

In many circumstances, the free-rider allegory does not provide an adequate description of reality. Moreover, even where there are free-rider concerns, the binary choice between IP and government subsidy completely misses the possibility for alternative institutional solutions.

First, reality is considerably more complex than the free-rider allegory suggests. There are many situations in which free riding does not undermine incentives to produce knowledge resources. Whether that is the case depends on contextual factors such as the type of investment required and the type of intellectual resources created. Many intellectual resources plainly are not subject to this concern; people produce them regularly without regard for misappropriation (Frischmann 20I2). Often, people innovate because their expected private benefits exceed their fixed costs, regardless of whether or not others free ride. Benefits conferred on "free riders" may be irrelevant to these kinds of incentives or even may add to them (Amabile 1996; Baron \& Shane 2007; Frey 2008; Lakhani \& Wolf 2005; Tirole \& Lerner 2002; Stock et al. 2013; von Hippel 2005).

Participation can be fun, intellectually stimulating, educational or service-oriented, among other things (Benkler 2006; Quiggin \& Hunter 2008; Loren 2008; Tushnet 2009; Zimmerman 2011; Schweik \& English 2012). Participation may not be effortless or free; it may require substantial investment. Regardless, the private value derived from participation may be sufficient, and external benefits conferred to others that use or consume the output (i.e., the intellectual resource) may be irrelevant to incentives to invest. Similarly, in many situations, people create, invent, and innovate because the anticipated returns from their own uses of the results are sufficient to justify the investment. A rich literature on user innovation demonstrates how many significant innovations result from users seeking to solve their own particular problems, needs, or curiosities (von Hippel 2005; Strandburg 2009: 871-88). People often engage in such activities without disabling concern over free riding and without reliance on government subsidies.

The point should be clear. Free riding does not necessarily reduce incentives to invest and does not inevitably lead to a social dilemma. Reality is considerably more complex than the free-rider allegory suggests, and there is no good reason for systematically marginalizing the many situations in which free riding does not reduce incentives to invest. Such myopia is inexcusable. Indeed, a myopic focus on the free-rider issue may distract researchers and policy makers from other social dilemmas that may be more important in some contexts. For example, some intellectual resources may be exploited in secrecy, as is recognized by trade secrecy laws and by patent law's disclosure requirements. Such 
resources do not suffer from free-rider problems, but from a different set of social dilemmas related to the social costs of secrecy. Another example arises in the user innovation context. Intrinsic or user motivations for innovation sufficient to overcome free-rider concerns, may not incentivize investments in codifying and disclosing those innovations for the benefit of society and in disseminating embodiments of those innovations for others' use (Strandburg 2010). While user innovators often disclose their innovations to other users because they can benefit when other users critique or improve upon them (Franke \& Shah 2003; Harhoff et al. 2003), recent studies show that many user innovators do not invest in disclosure and dissemination, again posing social dilemmas unrelated to the dominant free-rider allegory (Gault \& von Hippel 2009; von Hippel \& Demonaco 2013). We discuss various examples of other social dilemmas throughout this book.

Second, as is our focus here, the traditional binary of IP rights and government subsidy misses out on a wide variety of alternative institutions for solving social dilemmas involved in the production and management of knowledge resources, including free-rider problems (Merges 1996; Reichman \& Uhlir 2003; Raustiala \& Sprigman 2012). Unfortunately, comparative institutional analysis is limited in this area (Rai 1999; Frischmann 2000; Newell et al. 2008; Sarnoff 2013), as is more systematic analysis of interdependencies among various institutions.

We must emphasize how much contemporary analysis of the law and public policy of knowledge production rests on the traditional account of the basic public goods problem and binary set of solutions. That account shapes - if not determines-the set of baseline premises that undergird the legal and social institutions that structure the cultural environment and shape normative outcomes. Although our undertaking is emphatically positive and descriptive, we strongly believe that significant normative implications should eventually flow from a better understanding of knowledge commons. The bottom line is that the free-rider allegory and associated binary solution set rarely describe shared resource settings in a sufficiently complete manner to qualify as a useful theory for making predictions or prescribing solutions. Much more is needed.

\section{B. THE NEED FOR SYSTEMATIC EMPIRICAL STUDY OF KNOWLEDGE}

\section{COMMONS}

Much of the debate in IP law has pitted proponents of privatization as a means of incentivizing production of intellectual goods against proponents of a widely available public domain upon which cultural goods can be built. That discussion has often devolved into a disagreement over the relative importance of upstream incentives and downstream access for generating ideas and creative expression. As technology facilitates an increasingly extensive, varied landscape of social and cooperative projects that enable creativity and innovation, a third perspective has emerged. Books, articles, and scholarly discussion of such projects increasingly extol community production as a solution to the free-rider problems of cultural production (Benkler 2006). 
Recognizing the importance of community production, but concerned that the amorphous idea of "openness" might become the new one-size-fits-all panacean approach in rivalry with privatization and public subsidy, scholars have pointed out that many of the most interesting and important aspects of the information environment exist in the area between these extremes. The information environment is riddled with complex combinations of private intellectual property rights, contracts, and social norms that are partly open and partly closed, usable by members and sometimes by the public at large, though not always on a purely "free" basis. Examples of these knowledge commons-sometimes called "semicommons" (Smith 2000)—include such diverse institutions as public lending libraries, research universities, trade and craft organizations, and repositories of biological information. Default rules of intellectual property may be combined with licenses and contracts, with social norms and with cultural and other institutional forms to construct these knowledge commons, which depend on-but are built alongside and on top of-basic forms of knowledge and culture. Knowledge commons arrangements often are characterized by what Frischmann and Lemley term "spillovers": social benefits that flow from uses and reuses of information resources and sustain the dynamic character of the information environment (Frischmann \& Lemley 2007: 268-7I). Legal limitations on intellectual property rights support the possibility of constructing commons governance arrangements that allow resources to be used in ways that generate spillovers (Madison 2005a: 409).

Our knowledge commons framework emerges from our belief that the production and management of knowledge and information resources is an inherently social phenomenon, taking place over a wide range of scales and within a complex, overlapping variety of formal and informal institutional structures (Madison 2005b). Certainly, social production of cultural goods has become more salient and more economically important as a result of globalization and of the communications revolution symbolized by the Internet. Scholars are beginning to grapple with the realization that legal facilitation of innovation and creative production is not and cannot be confined to a simple set of property rules to incentivize individual innovative and creative efforts. Sustaining innovation and creativity is a matter of governance, using legal and other tools. The question for public policy, law, and legal theory becomes how best to use those tools to encourage the growth and persistence of creative, sustainable, and equitable cultural environments.

If commons are truly common, then they should be given a central place as research subjects, rather than either marginalized by conventional, overly simple private rights/ public domain dualism or uncritically extolled. The increasing salience of the community production alternative should motivate us to explore the details of the landscape of knowledge and information production systematically from an institutional standpoint and to identify where, when, and how knowledge governance regimes work to society's benefit. 


\section{The Institutional Analysis and Development Framework}

\section{A. MOTIVATION FOR A FRAMEWORK APPROACH IN THE NATURAL RESOURCE} CONTEXT

A group of scholars of commons regimes in the natural environment, spearheaded by the late Elinor Ostrom and her collaborators, have for decades been studying commons in the natural resource environment (Ostrom 2007). Examples of natural resources systems governed as commons include lobster fisheries, grazing pastures, forests, and irrigation systems (Ostrom 1990: 58-88; Acheson 2003). For each of these resources, previous scholars had diagnosed a similar underlying problem, often called, following Hardin (1968), a "tragedy of the commons" (Rose 2008: 4II). Given a pool of rivalrous resources that is presumptively open to all comers, such as a meadow for grazing sheep, and absent a mechanism for coordinating the actions of resource users (the owners of the sheep), the resources are likely to be overconsumed and under-replenished. If resource users act rationally and independently in pursuit of their own self-interest, without regard for the costs imposed on other users, the pool eventually will be destroyed. This "tragedy of the commons" illustrates a standard externality problem that manifests a failure of collective action. The "tragedy of the commons" story often is coupled with an assumption that tragedy can be avoided only by one of a binary set of choices: exclusionary property rights allocated via markets (Demsetz 1967: 348) and government intervention and regulation (Cornes \& Sandler 1996: 72-78). The work of commons scholars in the natural resource arena demonstrated the fallacy in this binary perspective by grounding theory in in-depth empirical study of the ways in which people actually organize and govern their use of common-pool resources.

Ostrom's approach to governance of natural resources broke with convention by recognizing the importance of institutions intermediate between private property and the state in solving problems of collective action. These intermediate institutions, sometimes called "limited commons" or "semicommons," are collective, locally organized, means for governing and making productive and sustainable use of shareable, but depletable, resources such as fish, water, and trees (Ostrom 1990: 88-90). The empirical research of Ostrom and other scholars demonstrates that solutions to these resource-sharing problems are various and highly contextual, and may be formal or informal. Such common-pool resources, or resource systems, often exist in complex institutional settings in which smaller commons are "nested" within larger ones, so that researchers must explore these institutions at different scales or levels of detail (Ostrom 2005: 58-62). Standard theoretic models, whether or not grounded in the presumption that a tragedy of the commons is present, can therefore be only the beginning of a much more complex analysis. The temptation to seek out regulatory panaceas based on universal models, whether through private property, state action, or even notions of community, must 
be resisted in favor of a more nuanced approach (Ostrom 2007). That approach begins with a research framework, guided by multiple theoretical possibilities and openness to considering the different variables that might affect outcomes. Only later, in light of the aggregation and analysis of data, does it become possible and meaningful to generalize and eventually to construct testable models.

As Ostrom explains, frameworks, theories, and models have different roles to play:

The development and use of a general framework helps to identify the elements (and the relationships among these elements) that one needs to consider for institutional analysis. Frameworks... provide the most general set of variables that should be used to analyze all types of settings relevant for the framework... They attempt to identify the universal elements that any relevant theory would need to include....

The development and use of theories enable the analyst to specify which components of a framework are relevant for certain kinds of questions and to make broad working assumptions about these elements. Thus, theories focus on parts of a framework and make specific assumptions that are necessary for an analyst to diagnose a phenomenon, explain its processes, and predict outcomes.... Microeconomic theory, game theory, transaction cost theory, social choice theory, public choice, constitutional and covenantal theory, and theories of public goods and common-pool resources are all compatible with the IAD framework....

One needs a common framework and family of theories in order to address questions of reforms and transitions. Particular models then help the analyst to deduce specific predictions about likely outcomes of highly simplified structures. Models are useful in policy analysis when they are well-tailored to the particular problem at hand. Models are used inappropriately when applied to the study of problematic situations that do not closely fit the assumptions of the model....(Ostrom 2005: 28-29)

\section{B. THE INSTITUTIONAL ANALYSIS AND DEVELOPMENT FRAMEWORK}

The Institutional Analysis and Development (IAD) framework was developed and used to structure a common set of research questions to apply across these diverse contexts. It has been successful in coming to some conclusions about the significance and interactions of various factors in facilitating effective management of natural resources (Ostrom 2007: $15181-82$ ). Based on the information obtained by applying their framework to structured case studies, these researchers developed theories and models for particular commons situations, designed experiments to test those theories, and used statistical methods to look for regularities across cases. Based on this empirical work, Ostrom advanced a set of design principles for successful natural resource commons. 


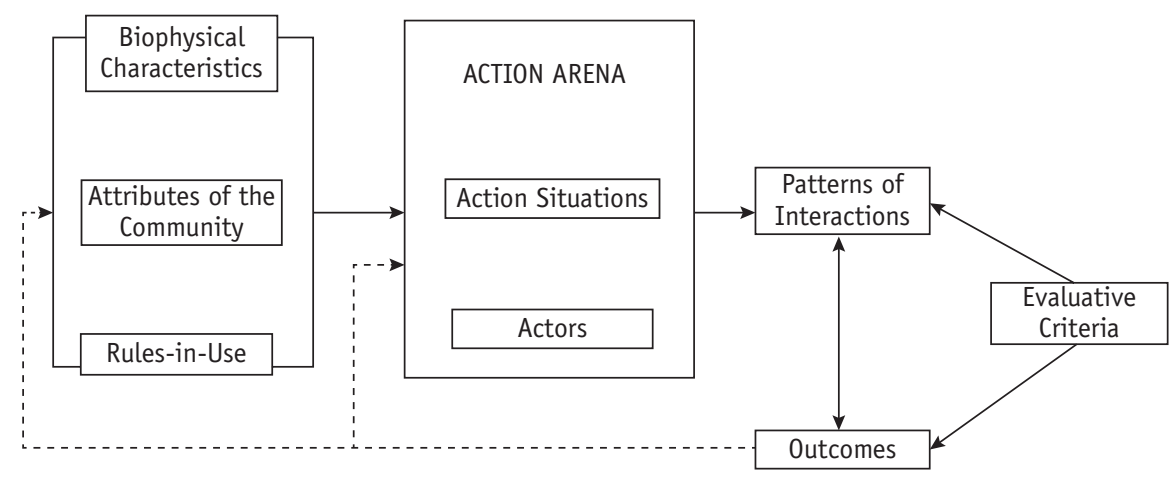

FIGURE I.I The Institutional Analysis and Development Framework.

The IAD framework for natural resource commons is illustrated in Figure I.I

On the left are represented a group of variables that are "exogenous" with respect to a particular set of interactions taking place in an "action arena" (Ostrom 2005: 13). The IAD framework identifies the important variables for analyzing the way that community members interact in a particular situation as biophysical characteristics, attributes of the community, and "rules-in-use." In the case of the lobster fishery, for example, these attributes might include the relevant biological characteristics of lobsters, such as the rates at which they age and reproduce; attributes of the community of fishermen, such as the proximity in which they live to others, the existence of familial relationships, and the skill sets needed for lobster fishing; and the rules-which are the net result of whatever informal and formal rules nominally apply to a particular situation - that actually govern the way that fishermen (and any other relevant actors) interact with one another and with the resource in various situations that arise (Ostrom 2007: 15184-85). The central portion of the figure identifies the variables that define the "action arena." An action arena "refers to the social space where participants with diverse preferences interact, exchange goods and services, solve problems, dominate one another, or fight (among the many things that individuals do in action arenas)" (Ostrom 2005: 14) - in other words, the place at which the exogenous variables combine in particular instances, leading over time to observed patterns of interactions and outcomes. A particular action arena involves specific action situations and specific actors, along with those actors' identities and roles. At the far right of the figure are the patterns of interactions, outcomes, and evaluative criteria that determine how the variables that are exogenous in a particular interaction may eventually respond and change.

The "tragedy of the commons" allegory makes assumptions about the biophysical characteristics (depletable), community (independent, self-interested rational actors), and "rules-in-use" (every fisherman for himself) that apply in the action arena of fishing for lobsters. It also assumes that independent fishermen are the only actors in the action arena and that the collective action problem posed by the "tragedy of the commons" is the only type of social dilemma involved in the situation. Under those assumptions, the 
outcome that ensues is scarcity, depletion, and, eventually collapse. Viewing the "tragedy of the commons" story through the lens of the IAD framework illuminates its empirical shortcomings. Lobsters are not purely depletable. They can, as a biological matter, reproduce and replenish the resource. The community does not consist of entirely independent actors. Fishermen and their communities have more complicated relationships, which permit them to cooperate, at least in some respects. The "rules-in-use" in the lobster fishery are more complex than "every fisherman for himself." As a result, the interactions in the lobster fishing action arena can produce very different outcomes than the tragedy of the commons story would predict. A successful commons governance regime may, however, require the community to resolve a nested set of social dilemmas over and above the basic collective action problem.

As a methodological matter, structuring a case study according to the IAD framework, involves asking specific questions about each of the sets of variables identified in Figure I.I, which assist the researcher in drilling down into the facts of a particular case (Ostrom 2005: 13-14). Questions about the biophysical characteristics, attributes of the community, and rules-in-use, for example, include the following:

- What boundaries define the shared resource pool? What is the source of supply and sustainability of the resource units? Under what conditions may resource units be appropriated from the pool?

- How does the population monitor and enforce rules regarding contribution and appropriation? What sorts of sanctions are available, and what sanctions are actually used? What conflict resolution mechanisms are in place?

- If the community relies on other populations in some respects, or if the population delegates some functions to subsidiary populations, what is the character of these relationships?

- In all instances, to what extent are these attributes inscribed in formal institutions of the state? To what extent are they inscribed in other formal, legal institutions, and to what extent are they inscribed in social norms or other social or cultural structures?

Employing the IAD framework to investigate a number of different real-world cases illuminated the diversity of possible combinations of exogenous variables that determine what actually happens in particular instances and, hence, the outcomes that result. The rules governing lobster fishing contribute to the activity's long-term sustainability, for example, but the patterns of interaction actually observed depend on the richness of the particular environment for lobsters, the degree to which rules are actually enforced, seasonal factors such as weather, and interaction with outside influences such as pollution and the state of the larger economy. Understanding the observed success or failure of a commons enterprise such as a lobster fishery may require accounting for all of these factors, even though it may turn out that outcomes are relatively impervious to some of them. 
The IAD framework thus allows researchers to move beyond the overly general assumptions of the "tragedy of the commons" story to investigate how resources actually are governed, structuring the empirical inquiry so that comparisons between cases are possible, while avoiding unwarranted assumptions related to particular theories or models.

\section{Developing a Framework for the Study of Knowledge Commons}

\section{A. LEARNING FROM AND ADAPTING THE INSTITUTIONAL ANALYSIS AND \\ DEVELOPMENT FRAMEWORK}

The IAD framework has proven fruitful in the natural resources context (The Economist 2008). We argue that the lessons learned by these scholars of natural resource commons caution against an overly simplistic view of community knowledge production and management. The devil is in the details. The nested, multi-tiered character of productive and sustainable knowledge and information systems and the diversity of attributes that contribute to successful governance regimes are key to understanding knowledge commons as mechanisms for knowledge production, collection, curation, and distribution in the context of modern information and IP law regimes. We therefore propose that Ostrom's approach to the systematized study of natural resource commons be adapted to study knowledge commons in the cultural environment. We use the "cultural environment" metaphor advisedly, following the work of Boyle (Boyle 1997: 108-12). The environmental metaphor for information law and policy-focusing on knowledge and information resources rather than physical or natural resources-offers an illuminating and useful starting point for this project.

Ostrom and her colleagues have taken preliminary steps toward understanding how the IAD framework might be used to investigate certain knowledge commons. Ostrom and Hess have analyzed the management of digital collections of existing knowledge resources, an admirable first step that signals the need for and plausibility of extending the IAD framework to the cultural environment (Ostrom \& Hess 2007).

The environmental metaphor has its limitations, however. We argue that the IAD framework must be modified and extended to account adequately for the wide variety of knowledge commons. Unlike commons in the natural resource environment, knowledge commons arrangements usually must create a governance structure within which participants not only share existing resources but also engage in producing those resources and, indeed, in determining their character. In fact, knowledge commons members often come together for the very purpose of creating particular kinds of knowledge resources. The relevant community is determined not by geographical proximity to an existing resource, but by some connection-perhaps of interest or of expertise-to the knowledge resources to be created. These characteristics of knowledge commons suggest that neatly separating the attributes of the managed resources from the attributes and rules-inuse of the community that produces and uses them is impossible. 
Just as the simple tragedy of the commons allegory is insufficient to specify the social dilemmas that must be overcome by a natural resource commons, the simple free-rider allegory is only one of the possible social dilemmas that are likely to confront a knowledge commons. Indeed, the characteristics of knowledge commons just described suggest that a more complex set of social dilemmas is likely to arise in the knowledge context. Here we give several illustrations of this point.

First, like the natural resource commons that Ostrom studied, knowledge commons not only allocate resource consumption opportunities but also must cope with challenges in coordinating and combining resources. In knowledge and information contexts, solutions to a range of coordination challenges are fundamental. Those who create, invent or innovate, and participate in similar intellectually driven, productive activities necessarily borrow from and share with others. It is impossible to divest oneself of that to which one has been exposed. Inevitably, the intellectual products of past and contemporary "producers" (creators, inventors, innovators, thinkers, and the like) serve as inputs into later productive activities. Producers necessarily borrow and share-and not in any fixed or small number of ways.

Second, the nonrivalrous and nonexcludable knowledge resources that make up the cultural environment are not naturally defined by boundaries that permit exclusion of users. Boundaries are built rather than found. They come from at least two sources. Intangible knowledge resources often are embodied in tangible product forms, which create boundaries. Additionally, law and other social practices may create boundaries around the intangible resources themselves, as, for example, in the case of the "claims" of a patent. The creation of boundaries is partly within and partly outside of the control of the members of a knowledge commons community and generates a series of social dilemmas to be resolved.

Third, knowledge and information resources must be created (or at least identified as knowledge and information resources) before they can be shared. Therefore, knowledge commons must manage coordination, combination, and competition issues relating both to resource production and to resource use within and potentially beyond the commons participants. The public goods character of knowledge resources necessitates consideration not only of dynamics internal to a commons community but also of relationships between commons and other, related institutions. Knowledge commons must confront questions of openness that may generate additional social dilemmas (Madison, Frischmann, \& Strandburg 2009: 368-69.)

Fourth, the nonrivalry of knowledge and information resources often rides on top of various rivalrous inputs (such as time or money) and may provide a foundation for various rivalrous outputs (such as money or fame). Knowledge commons must confront the social dilemmas associated with obtaining and distributing these rivalrous resources.

Finally, understanding a knowledge commons may require researchers to engage with the particular narratives of the community, which may be grounded in storytelling, metaphor, history, and analogy. The property scholar Carol Rose emphasizes the role of 
narratives, especially of origin stories, in explaining features of property regimes that are not determinable strictly on theoretical or functional grounds, particularly if one assumes that everyone begins from a position of rational self-interest (Rose 1994: 35-42). The stories that are told about knowledge commons, and by those who participate in them, are instructive with respect to understanding the construction, consumption, and coordination of knowledge resources. Particular histories, stories, and self-understandings may be important in constructing the social dilemmas that arise and in determining why a particular knowledge commons approaches them in a particular way.

Given the broad range of possible social dilemmas that may arise, a research framework can help researchers to develop, apply, and ultimately choose among an equally broad set of different relevant theories. Not only law but also economics, sociology, and history each may have much to offer in the future when interpreting case studies on knowledge commons. There is no reason now to limit the disciplinary conversation to only one of those fields - or to preempt future conversations about knowledge commons from blending them. For example, club theory, which distinguishes sharply between community members and outsiders, may be helpful in understanding the dynamics of patent pools but poorly suited to understanding Wikipedia, which is quite open in terms of membership, contributions, and participation in various aspects of the project. Patent pools manage shared resources in a fashion that is much less focused than Wikipedia on sustaining joint production. Consequently, club theory is not likely to be particularly helpful for a researcher studying Wikipedia. Other theories of cooperation might be better suited to the task. A research framework such as ours aims to systematize the investigation, facilitate a more rigorous evaluation by matching and testing of theories and models with observed phenomena, and, most generally, enable learning over time. We do not, for example, advocate adopting a strict definition in the first place that answers the question "what is a commons?" (Madison, Frischmann, \& Strandburg 2010b: 840-42). Nor do we adopt strict boundaries on the set of potentially relevant resources. The IAD framework in the natural resource domain was intended to be an inclusive method for conducting case-based research and collecting and comparing cases. By design, the IAD framework remains a work in progress, which is one of its strengths. We follow that tradition in proposing a framework for knowledge commons research. We designed our IAD-based framework based on our intuitions regarding the challenges and opportunities posed by governance institutions that feature shared resources, but we expect that it will be developed and honed as it is used.

\section{B. SPECIFYING A FRAMEWORK FOR STUDYING KNOWLEDGE COMMONS}

We illustrate our proposed framework for knowledge commons with the flow chart in Figure 1.2, which reflects the iterative and constructed character of the commons community, its knowledge or information resources, and its governing "rules-in-use." Figure I.2 is based on the IAD flow chart reproduced in Figure I.I (Ostrom 2005: I5), but it differs 


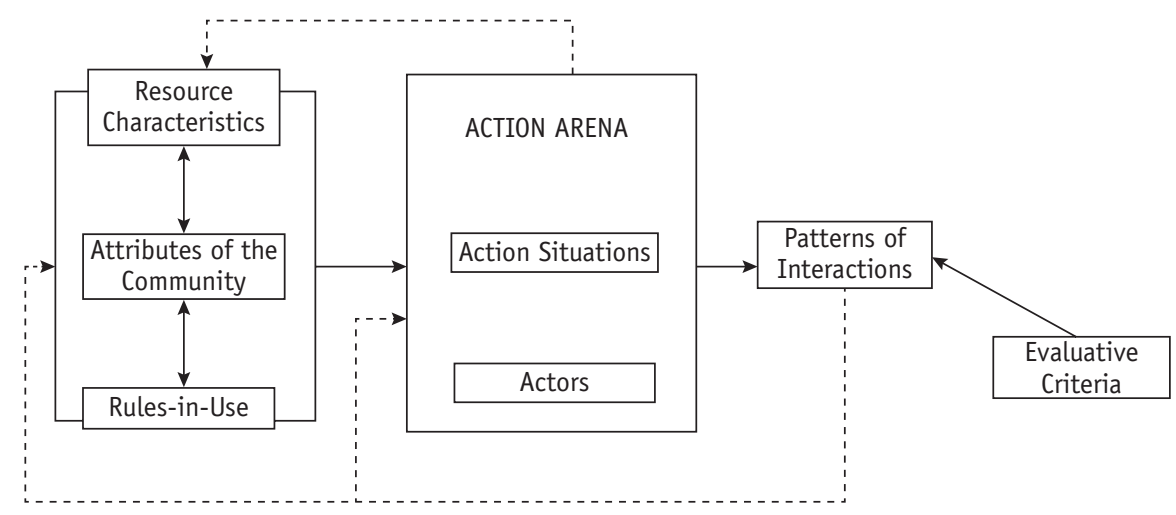

FIGURE I.2 The Knowledge Commons Framework.

in some key respects. Because of the more complex relationships among resources, participants, and governance structures in knowledge commons, relevant attributes may not divide as neatly into categories as they do when one is describing a pool of natural resources. Thus, in the left-most part of the chart, we place new emphasis on the interactions among and constructed or manufactured nature of the knowledge and information resources themselves, as indicated by the arrows between them. We also illustrate the way in which interactions in the action arena, by creating intellectual resources, can feed directly back into the characteristics of the resources being managed by a knowledge commons.

Figure 1.2 also collapses a distinction made in the original IAD framework between "patterns of interactions" that follow from the action arena, and outcomes that follow from the patterns of interaction. We argue that the patterns of interactions generated by the formal and informal rules systems of a knowledge commons are often inseparable from the outcomes it produces. How people interact with rules, resources, and each other, in other words, is itself an outcome that is inextricably linked with and determinative of the form and content of the knowledge or informational output of the commons. In an open source software project, for example, the existence and operation of the open source development collaborative, the identity of the dynamic thing called the open source software program, and the existence and operation of the relevant open source software license and other governance mechanisms are constitutive of one another.

With this general modified framework in mind, we now describe our proposed framework for empirical study of particular constructed cultural commons. Building on the high-level categories reflected in Figure 1.2, we now elucidate the categories of questions that should guide any specific investigation in more detail. The box, "Knowledge Commons Framework and Representative Research Questions," below, provides an

\footnotetext{
${ }^{7}$ See Jacobsen v. Katzer, 535 F.3d 1373, I381-82 (Fed. Cir. 2008) (concluding that violations of an open source software license can be remedied by injunction, in order to preserve the productive character of the open source community).
} 
overview of the framework for reference. During the course of a case study, the proposed framework of questions described below and in the box is used in two ways. First, it is used as a guide in planning interviews with relevant actors. Second, it is used as a framework for organizing and analyzing the information gained from interviews, review of relevant documents and related materials, and so forth. Though we describe the various "buckets" of questions in the framework sequentially, in practice the inquiry is likely to be iterative. Learning more about goals and objectives is likely to result in the identification of additional shared resources, understanding the makeup of the community will lead to new questions about general governance, and so forth. Moreover, we anticipate that the framework itself will evolve and be honed through use. Indeed, the questions in the box and the discussion below already reflect some reorganization and fine-tuning of the framework as presented in our original work (Madison, Frischmann, \& Strandburg 20roa) in response to our experience with the case studies in this book, as discussed in more detail in the concluding chapter.

\section{KNOWLEDGE COMMONS FRAMEWORK AND REPRESENTATIVE RESEARCH} QUESTIONS

\section{Background Environment}

- What is the background context (legal, cultural, etc.) of this particular commons?

- What is the "default" status of the resources involved in the commons (patented, copyrighted, open, or other)?

\section{Attributes}

\section{Resources}

- What resources are pooled and how are they created or obtained?

- What are the characteristics of the resources? Are they rival or nonrival, tangible or intangible? Is there shared infrastructure?

- What technologies and skills are needed to create, obtain, maintain, and use the resources?

\section{Community Members}

- Who are the community members and what are their roles?

- What are the degree and nature of openness with respect to each type of community member and the general public?

\section{Goals and Objectives}

- What are the goals and objectives of the commons and its members, including obstacles or dilemmas to be overcome?

- What are the history and narrative of the commons? 


\section{Governance}

- What are the relevant action arenas and how do they relate to the goals and objective of the commons and the relationships among various types of participants and with the general public?

- What are the governance mechanisms (e.g., membership rules, resource contribution or extraction standards and requirements, conflict resolution mechanisms, sanctions for rule violation)?

- Who are the decision makers and how are they selected?

- What are the institutions and technological infrastructures that structure and govern decision making?

- What informal norms govern the commons?

- How do nonmembers interact with the commons? What institutions govern those interactions?

- What legal structures (e.g., intellectual property, subsidies, contract, licensing, tax, antitrust) apply?

\section{Patterns and Outcomes}

- What benefits are delivered to members and to others (e.g., innovations and creative output, production, sharing, and dissemination to a broader audience, and social interactions that emerge from the commons)?

- What costs and risks are associated with the commons, including any negative externalities?

\section{The Background Environment: An Initial Conundrum}

When seeking to apply the IAD approach to knowledge commons, we immediately confront a conceptual challenge. Ostrom's inquiry begins by asking questions about the "biophysical characteristics" of the relevant resources. This inquiry takes as given a natural environment and natural resources that are to be shared and managed. In describing a knowledge commons, we must take a step back before describing the relevant characteristics of the shared resources to ask how we should define the environmental or contextual backdrop against which the knowledge commons operates. There is no clean way to separate a particular knowledge commons from its "natural" cultural background, because cultural activity is always grounded not only in the natural environment but also in human social interaction, the human-made material environment, laws, histories, practices, traditions, and social norms. Although there may not be one "natural" background environment for knowledge commons, it is nonetheless important, in investigating a knowledge commons, to understand the cultural environment within which it is nested. The inquiry into the characteristics of its shared resources, community, and governance institutions must be framed in relation to that background environment. An 
appropriate description of the background environment will lead to a more concise and useful description of the knowledge commons under investigation and a better understanding of the sources and significance of the social, political, and economic aspects of knowledge commons.

We identify two canonical "default" background environments for knowledge commons: a cultural environment without intellectual property rights, on the one hand, and an intellectual-property-based cultural environment on the other hand. In many cases, the background cultural environment for a particular knowledge commons will combine elements from these default regimes.

\section{a. The Default "Natural" Cultural Environment}

Despite the expansive scope of IP rights, a significant range of activities, practices, and intellectual resources remain outside the intended scope of IP regimes. This "natural" cultural environment includes cultural resources (including broad traditions, practices, disciplines, and concepts, as well as more specific artifacts and items of knowledge) that are excluded from IP regimes on subject matter grounds, material as to which IP protection has expired, and material that is excepted from IP coverage in certain circumstances (for example, via rules of fair use or fair dealing). Much of this natural cultural environment is in the public domain, and hence accessible and usable by anyone without the permission of anyone else, though the "natural" environment also includes the possibility for secrecy with respect to some resources.

When knowledge commons are constructed in arenas where IP rights do not apply, the most appropriate choice of background environment against which to describe them is a "natural" cultural environment unmediated by rights of exclusion or other regulation. The "natural" cultural environment also may be a useful baseline for investigating some knowledge commons where intellectual property protection is available for the relevant resources, but plays a marginal role. For example, the Associated Press was constructed initially as a means of managing the sharing of an intellectual resource (news) that was not protected by the standard forms of IP law (the First Amendment to the U.S. Constitution generally precludes copyright protection for facts). The AP was the plaintiff in the leading case that established an intellectual-property-like, but very limited, "hot news" doctrine barring a very specific type of misappropriation of factual information. ${ }^{8}$ Despite the existence of these limited IP-like rights, the AP knowledge commons is probably most concisely and clearly described in terms of its differences from the IP-free "natural" cultural environment.

For some resources, the "natural" cultural environment also includes the possibility of secrecy. A background culture of secrecy may provide the most useful default backdrop for describing some knowledge commons involving such resources. The norms of sharing access to magic tricks within the community of magicians, for example, arise in an environment of strong background norms of secrecy (Loshin 2008).

\footnotetext{
${ }^{8}$ See International News Service v. Associated Press, 248 U.S. 215 (1918).
} 


\section{b. The Default Proprietary Environments}

The two principal regimes of IP law-patent and copyright law-are the most salient alternatives to the "natural" environmental baseline described above. Patent rules vary somewhat from country to country, but generally time-limited patent rights are granted to the developers of an "invention" in some field of technology or human endeavor after an appropriate government agency examines a patent application (Nard, Madison, \& McKenna 2013: 19-27). Patents are available for a wide range of subject matter, but certain types of subject matter, such as natural phenomena and abstract ideas, are not eligible for patent protection. A patent applicant must demonstrate to the satisfaction of the patent examiner that the invention claimed in the application is new (or "novel," in the language of patent law) in that no one has invented it before; it is useful; it is nonobvious (in the language of American patent law) or possesses an "inventive step" (in most European systems), such that the invention represents a sufficiently great technical advance over the existing art; and it is adequately described in the application for the benefit of future adopters and adapters of the technology. The holder of a valid patent possesses a statutory right to exclude all others from using, producing, or selling the invention, subject to extremely limited exceptions for experimentation and research on the subject matter of the patent. Notably, however, patent rights expire after a relatively short term, typically twenty years. The invention covered by the patent then passes into the public domain. An example of a knowledge commons for which a patented environment serves as an appropriate baseline is a patent pool.

Copyright law departs from the "natural environment" norm for the cultural environment in similar ways, and for similar reasons, but applies to artistic and creative cultural expression rather than to technological invention. Like patent laws, copyright statutes vary in their details from country to country yet generally embody a set of core principles. The author of an "original" or creative work is granted a statutory entitlement to exclude others from reproducing, adapting, performing or disseminating that work to the public (Nard, Madison, \& McKenna 2013: 435-39). By comparison to patent doctrine, copyright doctrine generally incorporates a relatively broad range of exceptions and exclusions. It generally excludes subject matter that is functional rather than expressive (and therefore the subject of patent law) or that is too broad or abstract to be identified clearly as the specific product of a specific author. Even when a work is covered by copyright, the author's exclusive rights are generally subject to exceptions for uses that are deemed "fair use" in the United States or "fair dealing" in the United Kingdom, Canada, and some other countries, and to a range of other statutory exceptions, exclusions, and compulsory licenses. As with patents, expiration of the copyright delivers the covered material to the public domain. In general the term of copyright lasts far longer than the term of patent - the life of the author plus fifty years, in most countries, and the life of the author plus seventy years in the United States and European Union countries. Examples of knowledge commons for which copyright is an appropriate baseline are open source 
computer software under the General Public License (GPL) and open access repositories for academic publishing.

\section{The Basic Attributes of the Knowledge Commons}

The next step after choosing an appropriate characterization of the "natural" environment in which a particular knowledge commons resides is to identify and describe its basic attributes, which include its resources, participants, and goals and objectives. For each of these attributes, this section suggests a "basket" of questions to be asked during a case study. The resource characteristics and makeup of the community of a knowledge commons are generally co-determined with its goals and objectives and dependent upon its historical narrative. These are critical subjects of inquiry. In addition to baskets of questions directly aimed at describing the resources and community, the inquiry into basic attributes includes baskets of questions relating to goals and objectives, history, and narrative.

\section{a. Resources}

After choosing an appropriate baseline environment, the next step in investigating a knowledge commons is to identify the set of resources being pooled and the relevant community of actors. The resources being pooled in a given knowledge commons might appear to be obvious, such as patents in a patent pool, news items for a news service, or recordings for a database of music. But we caution against focusing too reflexively on the most obvious resources. For example, members of a patent pool might share other knowledge resources, such as pricing information, tacit knowledge about future research, or past failures. Often, it will take some consideration to identify the most salient description of the relevant resources. What resources are pooled and shared in an open source software community? Ideas? Computer code? Coding expertise? Debugging opportunities?

In many contexts, multiple types of resources might be shared within a knowledge commons. The dynamic character of intellectual and knowledge resources means that shared resources may not be fully independent of one another both in the sense that the value of one shared resource may depend on its relationship to other shared resources, and in the sense that any shared resource may arise from or be developed from a different shared resource. The multiple contributions to a single open source software project demonstrate both features. The durability of shared resources also must be considered. Patents and copyrights expire; tangible objects, in which patented inventions and copyrighted works of authorship often are embodied, may wear out or be consumed.

Our framework aims to be inclusive and aware of the variety of resources collected in knowledge commons. We avoid a focus solely on intellectual property assets or even on knowledge resources. Though its focus is on knowledge, a knowledge commons also may use, produce, and manage various rival resources. To understand the governance and effectiveness of a knowledge commons arrangement, it may be very important to study how these rival resources are managed. 


\section{b. Community}

Community members may be clearly and relatively simply identified—as they are in a patent pool—or the constitution of the community may be more complex. Does the open source software community consist of programmers alone? Does it include users of the code? People who submit comments or assist with debugging? Entrepreneurs who initiate meetings and dialogue or organize the community? People who develop, disseminate, and manage the relevant licenses? Those who monitor compliance with license terms? People who develop tools, host websites, and otherwise support the community? A single answer is not necessarily appropriate; each of these constituencies and their specific roles should be described (Schweik \& English 20I2).

\section{c. Goals and Objectives}

The goals and objectives of a knowledge commons often are critical to defining the resources it creates and shares, its membership, and the action arenas in which its members interact. Goals and objectives also are closely related to the social dilemmas that the commons must resolve. The goals and objectives of a natural resource commons often are evident from the common-pool resource itself and are defined by the problem of depletability or rivalrousness (e.g., removing lobsters from a fishery results in fewer lobsters for everyone else) and the risk that a common-pool resource will be exhausted by uncoordinated self-interested activity (e.g., unmanaged harvesting may jeopardize the sustainability of the lobster population).

Some knowledge commons have emerged and evolved over long periods of time and been influenced by large-scale historical, social, and/or economic forces that cannot be parceled neatly into an answer to the question, "what problem was being solved?" Contemporary research universities are, in one sense, examples of that phenomenon (Madison, Frischmann, \& Strandburg 2009). Commons are not always built; sometimes they emerge. Indeed, as discussed below, we believe that an inquiry into the history and narrative of a knowledge commons is always important to understanding it. Nonetheless, we believe it is usually sensible to speak of knowledge commons governance regimes as having particular goals and objectives. Moreover, often, knowledge commons are purpose-built.

While the particular goals and objectives of a knowledge commons will usually be closely related to the specific resources and community involved, the goals and objectives of a knowledge commons often will be tied to solving various problems and social dilemmas. Problems often addressed by knowledge commons include the production of intellectual goods to be shared, the overcoming of transaction costs leading to bargaining breakdown among different actors interested in exploiting the shared intellectual resource, the production of commonly useful platforms for further creativity, and so forth (Merges 1996: 1295-1301, 2005: 1514-19).

Some knowledge commons deploy IP rights to solve collective action, coordination, or transactions cost problems that exist apart from IP rights and perhaps would not be 
solvable without these rights (e.g., IP might be essential to facilitating collective action). Open source software projects, mediated by formal free and open source licenses and by informal communal structures for determining what code becomes part of the "authorized" code base, are examples of this type. Standard-setting enterprises also fit into this category, as do joint ventures for scientific research and development. These knowledge commons depend on each member's possessing certain intellectual property interests as a facilitator of participation.

Other knowledge commons are created, at least in part, to solve collective action, coordination, or transactions cost problems that exist only because of IP rights (Heller 1998: 625). In some of these cases, commons governance offers a defense against potential privatization of commonly useful shared resources and the possibility that an individual IP rights owner would "hold up" the enterprise as a whole. Examples of such arrangements might include "open source" commons constructed for basic biological building blocks such as the Single Nucleotide Polymorphism (SNP) consortium (Morgan 2003) or the publicly available databases of genomic sequences that are part of the Human Genome Project (Kumar \& Rai 2007). Formal licenses and related agreements assure that participants become part of what amounts to a mutual nonaggression pact that is necessary precisely because of the possibility that intellectual resources may be propertized. So long as the resource is part of a commons institution, it can be shared among commons members, and neither commons members nor outsiders are able to appropriate that resource, patent it, and then assert a patent claim against a commons member. Within commons, research proceeds more or less as it otherwise would, according to informal disciplinary norms and free of (or at least, less burdened by) undue anxiety about propertization and potential holdup.

A knowledge commons may also have the goal of mediating among communities with different default norms. Technology transfer institutions, which enable universities and other nonprofit research enterprises to deliver information resources (such as the technical knowledge described in patent specifications) to the private market, are examples of this type of commons (Jones \& Strandburg 2010: 13-17). The cultural environment inside the university is typically characterized by information sharing not governed by IP rights, even if IP rights are present as matters of form (Walsh et al. 2007: 1199-I200). Markets outside the university are governed largely by IP rights. Technology transfer institutions may constitute an institutional pool or commons that mediates these two regimes (Auerswald \& Branscomb 2003: 79-80). Similarly, open source projects have developed "boundary organizations" to mediate their relations with commercial firms (O’Mahony \& Bechky 2008).

Knowledge commons may also have less socially salutary goals. Most obvious is the case of members colluding to restrict competition (some believe that the Associated Press, for example, falls into this category (Baird 2005)). The inquiry into goals and objects should be sensitive to the possibility of such goals and objectives. But by requiring as an initial matter that knowledge commons operate via sharing of intellectual 
resources, we distinguish knowledge commons from cartels as such, which operate by sharing price and output information and which pose significant and obvious risks of anticompetitive behavior without offsetting welfare benefits (Viscusi et al. 2005: II632). The functional purpose of cartels differs from the purpose of the knowledge arrangements noted above; that is, cartels are not designed to create an open environment within which resources may be shared and productively used by members or to sustain individual members. The line between commons and cartels may be difficult to draw, however. Antitrust regulators have long faced the challenge of identifying illegitimate cartels disguised as legitimate patent pools and other knowledge-sharing institutions (Hovencamp 2012: \$\$30.4, 34.2).

These examples of the types of goals and objectives that may motivate the construction of knowledge commons arrangements are illustrative rather than exhaustive. Moreover, it may be the case-and may even likely be the case-that the motivations for any particular knowledge commons arise from a variety of considerations.

\section{d. History and Narrative}

All of the basic attributes of a knowledge commons - resources, community, and goals and objectives-often depend significantly on its narratives of creation and operation and on its history. Those narratives depend in turn on a variety of linguistic resources: the vocabulary and syntax that participants and observers use in describing the regime are keys to unlocking its origins, its operation, and even its future. The very phrase "patent pool," for example, has come to signify a specific set of legal expectations and criticisms. If one says "patent pool," an informed commentator thinks immediately of a self-governing arrangement and various antitrust considerations, rather than intellectual property problems and solutions, much less knowledge sharing.

Explicitly giving attention to history and narrative also encourages attention to evolutionary processes and avoidance of an overly static perspective. Looking at history can help answer the question of how the commons came to have its particular members, goals and objectives, and resources. History also reflects how a knowledge commons has changed and adapted over time and gives some basis for anticipating problems it may encounter in the future. Changes in a knowledge commons' narrative over time, or conflicts embedded within the narrative, can illustrate debates over purpose, which can illuminate the normative foundations of a commons and highlight points of conflict.

History and narrative also emphasize the importance of contextual details that are ignored or marginalized in an overly rationalist account of institutional design. They may provide information about individuals and their relationships to relevant institutions. They also are likely to be useful in uncovering details concerning the influence of power, position, politics, and personalities in a particular knowledge commons that may be swept under the rug in a more taxonomic approach to describing the basic attributes of a knowledge commons. 
3. Governance and Rules-in-Use

The governance of a knowledge commons can, and should, be investigated from a several angles. First, the governance of a knowledge commons is often reflected in its approach to openness, with respect both to resources and community. Second, the governance of a knowledge commons often is reflected in general governance structures, some of which arise from the background environment and some of which are specific to the particular knowledge commons. Third, the governance of a knowledge commons is reflected in specific rules and norms that apply to particular action arenas. These different perspectives on governance overlap to some degree, and all are relevant to describing the "rules-in-use" that apply to particular action situations.

\section{a. Degrees of Openness and the Character of Control}

The nonrivalrousness of knowledge resources often means that the community has a wide range of choice about the degree to which use of the resources and participation in the community is open to all comers or confined to some. These choices about the degree of openness are matters of governance, but are influenced by and co-determine the community's goals and objectives, its membership, and the characteristics of its resources.

Commons regimes are defined both by the degree of openness and control that they exhibit with respect to contributors, users, and resources and by the assignment of control, or custody, of the power to administer access. The rules-in-use of knowledge commons will reflect and delineate the degree of openness, particularly with respect to use of the resources by outsiders who do not contribute to resource creation. The inquiry into openness is often less relevant to natural resource commons arrangements, so we highlight it here. Natural resource commons generally are finite, depletable in consumption, often congested (such that overuse reduces the value of the remaining resources), and subject to tragic overconsumption, even taking into account differences in the depletability and renewability of different natural resource pools (Frischmann 2008: 166-68). Consequently, it is often necessary to limit access to a common-pool resource to members of a defined community, often geographically determined. The boundaries of the community sharing a resource tend to be coextensive with the boundaries of commons self-governance (Ostrom 1990: 6I-88). In many cases, a natural resource commons is open to members and closed to everyone else, and that is the end of the story.

Knowledge and information resources, by contrast, are not subject to the same constraints and are naturally shareable without a risk of congestion or overconsumption. Rarely does "too much information" diminish the value of individual items of information (Karjala 2006). It is entirely possible and desirable for a community to produce and/ or manage a cluster of cultural goods that is accessible to outsiders. Frischmann refers to this as "leveraging" the "nonrivalry" of intellectual resources (Frischmann 2009b: 810). One of the measures of the social benefit of knowledge commons may be the degree to which it disseminates its products to a wider audience. 
I. OPENNESS AS APPLIED TO RESOURCES. What do we mean by openness? Little ambiguity exists in most everyday contexts (e.g., an open door), but openness can be a confusing term when used to describe a knowledge or information resource. Openness, as we use it here, describes the capacity to relate to a resource by accessing and using it. In other words, the openness of a resource corresponds to the extent to which there are barriers to possession or use. Openness varies according to the costs of surmounting barriers (in terms of money, conditions, or other restrictions) to exploitation. Openness in this sense may encompass joint or shared access to and use of the resource (West 2007).

Barriers to possession or use of a resource may be natural or constructed. A resource may be open naturally because its characteristics prevent it from being possessed, owned, or controlled by anyone (consider, for example, the ocean). A resource also may be open as the result of social construction. That is, laws or rules may prohibit ownership or ensure a certain degree of openness. For example, copyright law grants protection over creative expression but excludes protection for ideas in order to maintain open access and the possibility of use. Patent law does likewise with respect to abstract ideas. Openness also may arise through social norms and customs among owners and users and through institutional design.

Openness and the vesting of control over openness are related. In part, both concepts may simply reflect choices regarding how best to manage resources. In the context of intellectual property pools, for example, management of the pooled resources may be vested in a central institution created specifically for that purpose, or it may be decentralized and vested in the hands of individual IP rights holders. Openness and the sources of control also reflect power and its distribution among potential possessors and users. Openness may be measured by the degree of control that is exercised by one person or group over the terms of access and use of a specific resource by others. Openness relies on social institutions; it is a relational variable that describes the structure of relationships among potential resource users.

II. OPENNESS AS APPLIED TO A COMMUNITY. As a resource or set of resources may have an open character, so may a community. As with resources, the degree of openness of a community is defined partly in functional terms, by natural and constructed attributes that define membership in the community, and partly in terms of power and other bases for relations among participants. (Accordingly, we focus much less on whether some social context is or is not a "community" according to predefined criteria and much more on the functional characteristics of that context.) As with openness applied to resources, openness with regard to a community describes an individual's capacity to relate to that community as a contributor, manager, or user of resources that make up the knowledge commons. Openness describes the extent to which there are criteria for or barriers to membership or participation in the creation or innovation processes that a 
knowledge commons is intended to support. Openness also describes the extent to which a particular community is accessible to and interconnected with related contexts, institutions, and social practices.

The degree of openness of a knowledge commons with respect to community has an internal dimension as well as an external one, as it reflects the degree to which participants in the commons collaborate with one another or otherwise share human capital as well as (or rather than) resources. For example, the participants in an intellectual property pool may specify rules regarding how resources are contributed to and withdrawn from the pool. The General Public License for open source computer programs specifies that membership in the community defined by users of the program is open to anyone. Anyone may add to, use, or redistribute the licensed program. Redistributors, however, must abide by the license term that they make the full source code of the program accessible to further users of the program. Moreover, in most open source software projects, only certain contributions are accepted into "official" versions of the code (Kelty 2008: 27-31). Although use and modification of the code for personal use are open to anyone, the ability to contribute to the shared resource is regulated.

In describing and assessing the degrees of openness and control that characterize knowledge commons, one should bear in mind more than just the conventional producer perspective by which information and knowledge shareability problems often are analyzed. Hardin's "tragedy of the commons" is typically understood as challenging markets and governments to offer ways to supply resources in the face of cooperation and competition problems (Ostrom 2008). In analyzing openness with respect to resources and communities, it is likewise tempting to limit the analysis to openness with respect to actual and potential resource producers.

The cumulative and aggregative character of knowledge is fundamental to human culture. Producers of knowledge and culture resources therefore are simultaneously users and consumers. It is important to consider whether and how the degree of openness of a knowledge commons accommodates the interests of users, as matters of both function and relation. In particular, a knowledge commons in the cultural environment may function as infrastructure, a platform, or collection of resources that serves as a foundation for further creation or innovation (Frischmann 2012). In the cultural environment, the tragedy of the commons that Hardin described may appear not as an undersupply of a resource prompted by overconsumption but instead as an undersupply prompted by the failure of the private market to aggregate user or consumer preferences for certain fundamental or "infrastructural" resources. This situation occurs, for example, in the context of basic research conducted within and across universities (Strandburg 2005: 97-99). The Internet itself constitutes a knowledge commons in a sense (as well as a collection of commons), and it is likely better characterized as an infrastructural resource that solves certain problems of consumption rather than as a resource that addresses problems of production. 


\section{b. General Governance Structures}

The general governance structures for a knowledge commons may include both exogenous elements arising from the background cultural environment and formal or informal leadership or decision-making structures specific to the knowledge commons. Here we identify several relevant clusters of variables that will be important to explore to gain an understanding of the general governance structure of a knowledge commons:

- entitlement structures and resource provisions;

- institutional setting (including markets and related firm and collective structures, social structures that accommodate the roles and interests of individual actors in the commons, and boundary organizations or mechanisms mediating the knowledge commons' interactions with external markets, the public domain, and other institutions);

- legal structures (including intellectual property rules, subsidies, contract and licensing law, antitrust provisions); and

- governance mechanisms of the commons (membership rules, resource contribution or extraction standards and requirements, conflict resolution mechanisms, sanctions for rule violation).

I. ENTITLEMENT STRUCTURES AND RESOURCE PROVisions. This cluster of questions is intended to address the boundaries around the resources themselves and to analyze how those boundaries are socially constructed, by law, technology, tradition, custom, or practice. Complicating the initial set of questions concerning what resources are contributed and subject to the commons arrangement, this part of the inquiry aims to understand how the resources are delineated, contributed, and made part of the commons.

The "natural" information environment contains an abundance of raw information resources, including inherited and experienced knowledge. Those resources often are transformed into information "things" (such as works of authorship, patented inventions, and commercial "trade secrets") and therefore into resources in the common pool via some cultural construct, such as the default copyright or patent law systems, via some other institution, such as a publishing industry producing books, films, or songs, or via some combination of these and other institutions, such as cultural practices or norms-including, to be clear, the agency of individual actors. Understanding a knowledge commons therefore requires understanding the mechanisms by which resources are provisioned to the commons, whether via legal entitlements or otherwise, and the nature of entitlements to use and consume those resources while they are part of that commons.

As with some natural resource pools that (when suitably managed) are self-sustaining and thus supply their own resources, in the cultural context commons resources may be inputs to the generation of additional resources. The follow-on invention is an obvious 
example. An essential attribute of the governance of a knowledge commons, therefore, is the way in which it allocates resources as they are produced dynamically. In a patent pool, for example, the patents themselves are resources constructed via rights of exclusion offered by patent law. As pool members develop follow-on inventions based on the pooled resources, the agreement by which the pool is constituted may obligate members to contribute patents covering those inventions to the pool. (Such grantbacks may raise antitrust concerns, ${ }^{9}$ which highlight the complexities of assessing the successes of commons governance as a knowledge and information management strategy.)

Boundaries in an information environment are likewise more obviously culturally constructed than their counterparts in the field of natural resources. Oceans, lakes, and rivers have beds and shores; forests yield to fields. Boundary maintenance is an important part of commons management in natural resources, but the maintenance question often has a reference point in naturally occurring boundaries. In the information environment, all boundaries ultimately depend on social and cultural constructs, that is, on what law or society recognizes as boundaries of relevant things and resources (Madison 2003). Accordingly, this cluster of questions is intended to help flesh out the connections between the construction of commons resources and their location-what we might call "nestedness"-in broader social and cultural systems.

il. institutional Setting. Knowledge commons are functional entities; they often serve participants in markets, industries, and firms. In such cases, it is important to understand the identities and roles of those institutions and how their functions relate to the pool and its members. The Manufacturers Aircraft Association, an example of an early, well-known patent pool, was organized in large part to facilitate the production of aircraft for military use during World War I. A full account of the MAA as a knowledge commons would need to explore not only the relationships among the members of the MAA but also the relationship between the MAA and the United States government.

The institutional and social setting of a knowledge commons also may include related collectivist enterprises. Each member of a pool may be part of a network structure that extends to related collectives, firms, individuals, groups, and social structures, including professional disciplines and social norms (Strandburg et al. 2006: 1301). For example, research scientists may be organized formally into pools or commons structures within formal institutions, such as universities, including schools, institutes, and departments. The shared discipline of a particular group of scientists will cross formal institutional boundaries and may be embedded in its own formal institutions. A scientist's functional network may include members of his or her own technical art and related arts along with researchers in different arts who share a related but distinct set of social norms related

\footnotetext{
9 See U.S. Dep't of Justice \& Fed. Trade Comm'n, Antitrust Guidelines for the Licensing of Intellectual Property $\$ 5.6$ (1995), http://www.usdoj.gov/atr/public/guidelines/0558.pdf.
} 
to sharing of information and knowledge. Networks in not-for-profit or educational research settings also will overlap to a degree with related networks in commercial environments. For example, researchers in university science departments will be interested in sharing information resources with researchers in corporate research-and-development groups (Strandburg 2009, 2010). A knowledge commons may bridge gaps created by the edges of formal institutional structures. Moreover, knowledge commons also may be situated in nonhierarchical and distributed institutional settings, in which participants are only loosely connected and sometimes are connected only by their participation in a particular project (Benkler 2006: 59-90).

III. LEGAL STRUCTURES THAT AFFECT THE COMMONS. Although industry, market, and networked institutional structures are essential reference points for many knowledge commons, positive law and direct government involvement with a particular commons may likewise be keys to understanding it. We distinguish between law that creates and enforces the entitlements that sustain information works, on the one hand, and law that is specifically addressed to knowledge commons themselves, on the other hand. In some circumstances, law can reinforce and sustain knowledge commons that are determined by legislators or judges to be welfare-enhancing. For example, market conditions or technologies might be such that some kind of information collective would be useful, but fear of prosecution under antitrust law or relevant IP law may be a barrier to the emergence of the pool. In such a case, a safe harbor for knowledge sharing of a sort may emerge, either via legislation or judicial decision. An exemption or more deferential treatment from antitrust scrutiny for parties engaged in a form of concerted activity, or intended to engage in concerted activity, might be adopted (Hovencamp 2012: \$36).

Legal rules may create subsidies or safe harbors for knowledge commons in ways other than by relieving at-risk parties from potential liability. For example, income-tax regimes may permit (or limit) the deduction of research expenses by firms, nonprofit enterprises, and/or research collectives. In the U.S. patent statute, the section that bars patenting inventions that are "obvious" in light of prior art in the relevant technical field formerly excluded prior art from consideration if the patent applicant and the producer of the relevant prior art were part of a common "joint research agreement." ${ }^{10}$ Laws designed for one purpose also may effectively promote collaborations or collectives in ways not intended by their drafters. Such rules may become part of the constitution of a knowledge commons, even if they were not designed to do so. For example, Jessica Litman explains the persistence of a legal regime subsidizing jukeboxes in American copyright law along similar lines (Litman 2002: 35I-53). A compulsory

\footnotetext{
${ }^{10} 35$ U.S.C. $\$ \mathrm{IO}_{3}(\mathrm{c})(2)$ (2012). As part of the America Invents Act of 2012, applicable to patents that issue based on applications filed after March I6, 2013, that section was rewritten, and its provisions relocated to the section that requires that patentable inventions be novel. See 35 U.S.C. $\$$ IO2(c)(2) (2012).
} 
license permitting owners of coin-operated record players to use copyrighted American music without authorization was initially incorporated into the copyright statute to prevent copyright holders from monopolizing adjacent markets for performances. Over time, the rationale for the subsidy became less significant, but the statute was retained because a new entity emerged to support its continued existence-companies that manufactured and distributed jukeboxes. The compulsory license enabled a form of sharing of recorded music that was mandated by law rather than by consent of the individual rights owners.

IV. ENDOGENOUS GOVERNANCE MECHANISMS. Understanding the governance mechanisms particular to a given knowledge commons is at the heart of the analysis. In Ostrom's work, the degree of self-governance is an important characteristic of a resource pool (Ostrom 1990: 29-55). Membership in natural resource commons often entails rights not only to contribute to and extract from the pool but also to participate in governance processes for adopting and modifying the relevant rules of participation. Endogenous governance mechanisms may include formal or informal leadership roles, general approaches to decision making, conflict resolution procedures, technological platforms for communication and other general purposes, and so forth.

The inquiry into the governance mechanisms of a knowledge commons overlaps to some extent with the inquiry into its openness. The focus shifts, however, from access to shared resources to participation in decision making about how the resources will be produced and managed. Who decides who may be a member of the commons and what does membership entail? How are resource contribution and extraction monitored and, if necessary, limited? What sanctions and dispute resolution mechanisms are provided for dealing with conflict or misconduct? To what extent do the self-governance mechanisms of the commons rely on or incorporate formal legal mechanisms, and to what extent do they rely on or incorporate other, nonlegal institutions, technologies, or social structures?

For example, in the context of the General Public License for open source computer programs, commons membership is defined in part by the terms of the license and in part by use of the program, which, according to the terms of the license, constitutes assent to its terms. ${ }^{11}$ Violation of the terms of the open source license, for example by distributing a copy of a program without including a copy of the program's source code, purports to terminate membership in the open source community automatically, by operation of law. Enforcement of the license regime typically is not pursued by individual contributors to the open source commons. Instead, the Free Software Foundation, a freestanding nonprofit entity dedicated to advocacy on behalf of "free" software and accompanying

${ }^{11}$ See Free Software Foundation, GNU General Public License, http://www.gnu.org/licenses/gpl.html, \$9. 
open source license terms undertakes responsibility for enforcement (Free Software Foundation 2013).

Effective enforcement of the rules-in-use of a commons depends on the availability of means to monitor members' compliance with those rules. Before the emergence of the Internet, research on self-governing communities emphasized the size of the community and the distances between its members as key variables in the effectiveness of a monitoring system. Accordingly, conventional wisdom expected that informally governed groups would be relatively rare and believed that success would require modest size and relative homogeneity of interest. As Benkler (2006: 29-127) and Cohen (2006: 37-43) each argue, networking technology offers not only expanded potential for community development and resource aggregation but also the potential for increased monitoring and enforcement. (As the next section makes clear, that is not automatically a good thing, but it can help explain commons functioning.) Examination of a pool should include assessment of whether and how it is embedded in network technologies that perform or facilitate governance functions.

Research on natural resource commons also emphasizes that effective self-governance typically requires formal access to public sanctioning and/or enforcement mechanisms. Without the threat of seizure or attachment or injunction, community-based or purely norm-based mechanisms may lack sufficient bite to sustain the commons. In the context of knowledge commons, it is not yet clear when and whether it is important for commons governance to be backed up by legal enforcement. Indeed, many social normsbased governance regimes have been identified and studied (Raustiala \& Sprigman 20I2). In the open source computer software area, for example, courts only recently have begun to consider the enforceability of the licenses. For the most part, breaches are handled by informal norms.

\section{c. Rules and Norms for Particular Action Arenas}

A given knowledge commons may involve a number of different types of interactions among members or "action arenas." Often, these action arenas will be closely related to the community's goals and objectives. Over and above the exogenous and internal general governance mechanisms of a knowledge commons, the rules-in-use of a particular action arena may be determined by rules or norms specific to that arena. It will probably be important to analyze how the basic attributes of a knowledge commons play out in a number of its action arenas to get a full understanding of how that commons functions.

\section{Patterns and Outcomes Emanating from a Particular Action Arena}

Finally, the analysis of a knowledge commons should include an inquiry into its patterns of interactions and outcomes. The outcomes of a knowledge commons typically will take two forms, which in a particular case often will be inextricably linked. With respect to 
knowledge and information resources, a knowledge commons usually will produce some intellectual or knowledge-related (or material) output. Thus, the MAA enabled the production of airplanes. The Linux open source project supports the Linux computer program. Wikipedia produces Wikipedia.org. The AP enables the production of newspapers and other news resources.

In addition, the social patterns that emerge from the construction and governance of a knowledge commons may themselves constitute ongoing, constantly refreshed commons outcomes. Many of the companies that were parties to the original MAA agreement combined via merger and acquisition by 1929 to form the Curtiss-Wright Corporation, which is still a significant defense contractor today (Patillo 1998:80-8I). The Linux project and Wikipedia are notable not only for their production of complex industrial-scale products but also for their production of networks of contributors, distributed broadly in space and time, for whom participation in the commons is an important and meaningful individual and social practice (Benkler 2006: 65-74). The AP and other wire services have cultivated and retained identities as distinct and productive enterprises despite the fact that much of what they publish is created by their members. The jamband community is a recognized community that defines itself partly via its practices of archiving and sharing jamband performances.

The inquiry into outcomes should focus explicitly on any costs or harms associated with the commons as well as on its benefits. Knowledge commons should be assessed in light both of whether and how they serve their self-identified goals and objectives and of any collateral consequences. The patterns and outcomes bucket of questions should aim both to identify the outcomes of the commons under study and to describe relevant criteria for evaluating those outcomes. Often, the evaluation of outcomes will begin with the identified goals and objectives of the community. The community may change its goals over time, and specific action areas may lead to the development of more fine-grained objectives that provide further basis for evaluation. Moreover, interactions with nonmembers may provide additional outcomes to evaluate.

Since the eventual goal of this research is to extract generalizable knowledge that will be useful for policy makers, the evaluation of outcomes raises difficult and important issues about how to derive metrics that will permit comparative institutional analysis. The evaluation of success is explicitly normative; for example, one can ask about whether a community met its internal goals and objectives or about its overall impact on the welfare of society. Comparing knowledge commons arrangements to one another requires comparable outcome metrics. For similarly situated communities with similar objectives, it may be relatively straightforward to develop appropriate metrics on a case-by-case basis. If one wants to compare differently situated communities with different objectives, the task is harder. Devising metrics that allow one to compare knowledge commons to other institutions for producing innovation and creativity may be even more difficult. The design of outcome metrics, which is a general challenge to comparative institutional analysis, is a subject for further research. 


\section{a. Solutions and Benefits}

We have noted that knowledge commons in the cultural environment emerge or are created for a variety of reasons: as solutions to collective action or other transactions cost problems unrelated to legal intellectual property, as solutions to problems that arise from the nature of intellectual property entitlements, as solutions to boundary-spanning dilemmas, and as reactions to "infrastructure"-type problems stemming from the market's inability to aggregate individual demand for standards or platform resources- the inverse of the standard tragedy-of-the-commons diagnosis. The pool of potential knowledge commons cases is, therefore, quite broad, and the range of possible solutions and benefits they produce is likewise broad.

For any specific knowledge commons, the inquiry into solutions and benefits should address not only the problems that the commons appears to be designed to solve and precisely how and whether it solves those problems but also whether the commons succeeds in generating and sustaining spillovers and contributing to a dynamic cultural environment more broadly. Quantifying or otherwise documenting the latter type of outcome may be particularly difficult, because the benefits of spillovers often accrue not only to direct consumers of the creative output of the commons, but to other members of society. As a result, assessments of success may, of necessity, take comparative rather than absolute form. Indeed, both the original IAD framework and our adaptation are intended for comparative institutional analysis. What kinds of comparisons might be relevant and useful as benchmarks in the knowledge commons setting? Researchers might ask about the respects in which commons governance helps to achieve outcomes (whether in terms of resources or community or both) different than (if not necessarily better than, in all cases) the outcomes achieved by attempts to solve those problems using other institutional regimes, such as private rights allocated in markets, or government regulation.

\section{b. Costs and Risks Associated with a Cultural Commons}

A knowledge commons approach often may involve a trade-off between the benefits anticipated from the commons, such as the dynamic welfare enhancements expected from open sharing, and the costs and risks associated with cooperation between those who might otherwise compete to provide knowledge resources in a market setting. In conventional law-and-economics terms, these costs and risks are fairly well understood. Importantly, they are in many instances better understood and easier to describe and quantify than the dynamic benefits that knowledge commons may supply. For example, institutions that enable firms to share access to pooled information resources may also facilitate cooperation along lines that may be anticompetitive and therefore socially harmful: agreements to raise and fix costs and agreements to reduce output. Knowledge commons also involve administrative costs associated with constructing, monitoring, and enforcing compliance with the rules of the pool. Here again the analysis is comparative. Both costs and benefits associated with producing particular information resources 
must be compared to the costs and benefits associated with producing the same kind of information resources by IP-based market transactions, government subsidy, or some alternative system.

\section{Conclusion}

Applying an environmental metaphor pioneered by earlier intellectual property law scholars, we analogize information and knowledge resources in the cultural environment to physical resources in the natural environment. We identify a set of knowledge commons, or pools of information resources, that serve functions in the cultural environment similar to the functions provided by common-pool resources in the natural environment. These knowledge commons serve as alternatives to purely private rights of exclusion and to government intervention in solving a variety of underproduction and overconsumption problems associated with an unmanaged or "natural" resource. Although knowledge commons exist for a variety of purposes, we hypothesize that they are often welfare-enhancing, because they solve the problems associated with producing nonrival information resources, while promoting knowledge distribution and valuable information spillovers.

We argue that understanding the origins and operation of knowledge commons requires case studies aimed at empirical assessment of a variety of attributes whose role and importance cannot be specified in advance based on simple models or our current understanding. Borrowing from Ostrom's Institutional Analysis and Development framework, we suggest a framework that should guide case studies of knowledge commons in exploring the ways in which information resources and resource commons are structured by default rules of exclusion, and the ways in which members of these pools manage participation in the collection, production, preservation, and extraction of information resources.

We offer the framework described in this chapter as a template for ongoing case study investigations of knowledge commons across a broad variety of domains. The case studies collected in this volume represent a small step in that direction. We hypothesize (and expect) that approaching the study of knowledge commons as an integrated field of research will elevate collective, intermediate solutions to a place of significance in accounts of property regimes and diminish skepticism about the range of situations that are amenable to collectively governed, "open” approaches to knowledge production. Case studies will also call attention to the designed character of both the cultural and the legal environments in which knowledge and information policy problems reside. Like Ostrom's studies of natural resource commons, systematic analyses of knowledge commons across a wide range of collected case studies are likely to lead us to doubt panacea prescriptions drawn from overly simplistic models. Understanding how knowledge commons work should enable better design of knowledge-producing and knowledge-distributing institutions generally. 
The existing scholarly literature reports various case study investigations of creative institutions grounded in social norms (Schultz 2006), transactions cost economics (Merges 1996), and even history and anthropology (Kelty 2008), all of which may be profitably aggregated and recast as examples of knowledge commons. One step in that direction is our application of the framework to analyze universities as cultural commons (Madison, Frischmann, \& Strandburg 2009). Collecting and reconstructing this literature using the clusters of questions listed above will, in our estimation, yield new insights into the emergence and effective functioning of knowledge commons. Going forward, and beginning with the cases included in this volume, we anticipate developing an inventory of new commons case studies. We also hope other scholars will consider using this framework as part of their own work. Over time, we hope that the results of further case studies will yield not only better descriptive information regarding knowledge commons but also refinements to the knowledge commons framework and to the above clusters of questions. In a real sense, the study of commons is itself a knowledge commons, and our own three-part collaboration is a nested commons within the scholarly community that studies commons.

\section{Acknowledgments}

Professor Strandburg acknowledges the generous support of the Filomen D'Agostino and Max E. Greenberg Research Fund.

\section{References}

James M. Acheson, Capturing the Commons: Devising Institutions to Manage the Maine Lobster Industry (University Press of New England 2003).

Teresa M. Amabile, Creativity in Context (Westview Press 1996).

Philip E. Auerswald \& Lewis M. Branscomb, Start-ups and Spin-offs: Collective Entrepreneurship Between Invention and Innovation, in THE EMERgence OF ENTREPRENEURShip Policy: Governance, Start-ups, and Growth in the U.S. KNowledge EConomy 6I (David M. Hart ed., Cambridge University Press 2003).

Douglas G. Baird, The Story of INS v. AP: Property, Natural Monopoly, and the Uneasy Legacy of Concocted Controversy, in Intellectual Property Stories 9 (Jane C. Ginsburg \& Rochelle Cooper Dreyfuss eds., Foundation Press 2005).

Robert A. Baron \& Scott A. Shane, Entrepreneurship: A Process Perspective (Cengage Learning 2007).

Yochai Benkler, The Wealth of Networks: How Social Production Transforms Markets and Freedom (Yale University Press 2006).

Enrico Bertacchini et al. eds., Cultural Commons: A New Perspective on the Production and Evolution of Cultures (Edward Elgar Publishing 20i2). James Boyle, A Politics of Intellectual Property: Environmentalism for the Net?, 47 Duke L.J. 87 (1997). 
Julie E. Cohen, Pervasively Distributed Copyright Enforcement, 95 Georgetown L.J. I (2006). Richard Cornes \& Todd Sandler, The Theory of Externalities, Public Goods, And Club Goods (2d ed., Cambridge University Press 1996).

Harold Demsetz, Toward a Theory of Property Rights, 57 Am. Economic Rev. 347 (1967).

Harry T. Dykman, Patent Licensing Within the Manufacturer's Aircraft Association (MAA), $46 \mathrm{~J}$. Patent Office Society 646 (1964).

Nikolaus Franke \& Sonali Shah, How Communities Support Innovative Activities: A Exploration of Assistance and Sharing among End-Users, 32 ReSEARCH POLICY I57 (2003).

Free Software Foundation, What Is Free Software and Why Is It So Important for Society?, http:// www.fsf.org/about/what-is-free-software (accessed June 16, 2013).

Bruno S. Frey, What Values Should Count in the Arts? The Tension between Economic Effects and Cultural Value, in Beyond Price. Value in Culture, Economics and the Arts (Michael Hutter \& David Throsby eds., Cambridge University Press 2008).

Brett M. Frischmann, Innovation and Institutions: Rethinking the Economics of U.S. Science and Technology Policy, 24 Vermont. L. Rev. 347 (2000).

Brett M. Frischmann, Environmental Infrastructure, 35 ECOLOGY L.Q. I5I (2008).

Brett M. Frischmann, The Pull of Patents, 77 Fordham L. Rev. 2143 (2009a).

Brett Frischmann, Spillovers Theory and Its Conceptual Boundaries, 5 I William \& MaRY L. Rev. 80 I (2009b).

Brett M. Frischmann \& Mark A. Lemley, Spillovers, io7 Columbia L. Rev. 257 (2007).

Brett M. Frischmann, Infrastructure: The Social Value of Shared Resources (Oxford University Press 2012).

Brett M. Frischmann, Two Enduring Lessons from Elinor Ostrom, 9 J. of Institutional ECONOMICS 387 (2013).

Fred Gault \& Eric A. von Hippel, The Prevalence of User Innovation and Free Innovation Transfers: Implications for Statistical Indicators and Innovation Policy (MIT Sloan School of Management Working Paper 2009), http://evhippel.files.wordpress.com/2013/08/ fred-and-eric-ssrn-2009.pdf.

Wendy J. Gordon, Harmless Use: Gleaning from Fields of Copyrighted Works, 77 Fordham L. REV. 24II (2009).

Garrett Hardin, The Tragedy of the Commons, I62 SCIENCE 1243 (1968).

Dietmar Harhoff, Joachim Henkel \& Eric von Hippel, Profiting from Voluntary Information Spillovers: How Users Benefits by Freely Revealing Their Innovations, 32 ResearCH POLICY 1753 (2003).

Michael A. Heller, The Tragedy of the Anticommons: Property in the Transition from Marx to Markets, in HARVARd L. Rev. 62I (1998).

Charlotte Hess, Constructing a New Research Agenda for Cultural Commons, in Cultural Commons: A New Perspective on the Production and Evolution of Cultures (Enrico Bertacchini et al. eds., Edward Elgar Publishing 20I2).

David A. Hoffman \& Salil K. Mehra, Wikitruth Through Wikiorder, 59 Emory L.J. I5I (2009). Herbert Hovenkamp et al., IP and Antitrust: An Analysis of Antitrust Principles Applied to Intellectual Property Law (Aspen Publishers 20i2).

Patrick L. Jones \& Katherine J. Strandburg, Technology Transfer and an Information View of Universities: A Conceptual Framework for Academic Freedom, Intellectual Property, Technology Transfer and the University Mission (Feb. 22, 2010) (unpublished manuscript, on file with authors). 
Dennis S. Karjala, Congestion Externalities and Extended Copyright Protection, 94 Georgetown L.J. 1065 (2006).

Christopher M. Kelty, Two Bits: The Cultural Significance of Free Software (Duke University Press 2008).

Sapna Kumar \& Arti Rai, Synthetic Biology: The Intellectual Property Puzzle, 85 Texas L. Rev. I745 (2007).

Karim R. Lakhani \& Robert G. Wolf, Why Hackers Do What They Do: Understanding Motivation and Effort in Free/Open Source Software Projects, in Perspectives on Free ANd Open Source Software (J. Feller et al. eds., MIT Press 2005).

Mark A. Lemley, Property, Intellectual Property, and Free Riding, 83 Texas L. Rev. I03I (2005). Jessica Litman, War Stories, 20 CARdozo ARTs \& ENT. L.J. 337 (2002).

Lydia Pallas Loren, The Pope's Copyright? Aligning Incentives with Reality by Using Creative Motivation to Shape Copyright Protection, 69 Louisiana. L. ReV. I, iI (2008).

Jacob Loshin, Secrets Revealed: How Magicians Protect Intellectual Property Without Law, in LAw AND Magic: A Collection of Essays (Christine A. Corcos ed., Carolina Academic Press 2008).

Michael J. Madison, Rights of Access and the Shape of the Internet, 44 Boston College L. Rev. $433(2003)$.

Michael J. Madison, Rewriting Fair Use and the Future of Copyright Reform, 23 CARDOzO ARTs \& ENT. L.J. 39i (2005a).

Michael J. Madison, Law as Design: Objects, Concepts, and Digital Things, 56 CASE Western. Reserve L. Rev. 38I (2005b).

Michael J. Madison, Brett M. Frischmann, \& Katherine J.Strandburg, The University as Constructed Cultural Commons, 30 Washington University J. Law \& Policy 365 (2009).

Michael J. Madison, Brett M. Frischmann, \& Katherine J. Strandburg, Constructing Commons in the Cultural Environment, 95 Cornell L. Rev. 657 (2010a).

Michael J. Madison, Brett M. Frischmann, \& Katherine J. Strandburg, Reply: The Complexity of Commons, 95 Cornell L. Rev. 839 (2010b).

Robert P. Merges, Contracting into Liability Rules: Intellectual Property Rights and Collective Rights Organizations, 84 California L. Rev. 1293 (1996).

Robert P. Merges, A Transactional View of Property Rights, 20 Berkeley TeCH. L.J. I 477 (2005).

Michael Morgan, New Paradigms in Industry: The Single Nucleotide Polymorphism Consortium, in The Role of Scientific and Technical Data and Information in the Public Domain: Proceedings of a Symposium i94 (Julie M. Esanu \& Paul F. Uhlir eds., National Academies Press 2003).

Craig Allen Nard, Michael J. Madison, \& Mark McKenna, The law of Intellectual Property (4th ed., Aspen Publishers 2013).

Richard Newell, Arti Rai, Jerome Reichman, \& Jonathan B. Wiener, Intellectual Property and Alternatives: Strategies for Green Innovation (Chatham House Energy, Environment and Development Programme Paper No. o8/03, December 2008).

Siobhán O’Mahony \& Beth A. Bechky, Boundary Organizations: Enabling Collaboration Among Unexpected Allies, 53 Administrative Science Q. 422 (2008).

Elinor Ostrom, Governing the Commons: The Evolution of Institutions for Collective Action (Cambridge University Press 1990).

Elinor Ostrom, Understanding Institutional Diversity (Princeton University Press 2005). 
Elinor Ostrom \& Charlotte Hess, A Framework for Analyzing the Knowledge Commons, in Understanding Knowledge as a Commons: From Theory to Practice 4I (Charlotte Hess \& Elinor Ostrom eds., MIT Press 2006).

Elinor Ostrom, Tragedy of the Commons, in The New Palgrave Dictionary of Economics (Steven N. Durlauf \& Lawrence E. Blume eds., 2d ed. 2008), http://www.dictionaryofeconomics.com/article?id=pde2008_Too0193.

Elinor Ostrom et al., Going Beyond Panaceas, io4 Proceedings of the National Academy of SCIENCE U.S. 15176 (2007).

Donald M. Pattillo, Pushing the Envelope: The American Aircraft Industry (University of Michigan Press 1998).

John Quiggin \& Dan Hunter, Money Ruins Everything, 30 Hastings Comm. \& EnT. L.J. 203 (2008).

Arti K. Rai, Intellectual Property Rights in Biotechnology: Addressing New Technology, 34 WAKE Forest L. REV. 827 (1999).

Kal Raustiala \& Christopher Sprigman, The Knockoff Economy: How Imitation Sparks InNOvation (Oxford University Press 2012).

J. H. Reichman \& Paul F. Uhlir, A Contractually Reconstructed Research Commons for Scientific Data in a Highly Protectionist Intellectual Property Environment, 66 Law \& ConTemp. PROBS. 315 (2003).

Reporters of the Associated Press, Breaking News: How the Associated Press Has Covered War, Peace, and Everything Else (Princeton Architectural Press 2007).

Carol M. Rose, Property and Persuasion: Essays on the History, Theory, and Rhetoric of Ownership (Westview Press 1994).

Carol M. Rose, Big Roads, Big Rights: Varieties of Public Infrastructure and Their Impact on Environmental Resources, 50 ARIzONA L. Rev. 409 (2008).

Joshua D. Sarnoff, Government Choices in Innovation Funding (with Reference to Climate Change), 62 EMORY L.J. 1087 (2013).

Mark F. Schultz, Fear and Norms and Rock \& Roll: What Jambands Can Teach Us About Persuading People to Obey Copyright Law, 2i Berkeley TeCH. L.J. 65I (2006).

Charles M. Schweik \&Robert C. English, Internet Success: A Study of Open-Source Software Commons (MIT Press 2012).

Carl Shapiro, Navigating the Patent Thicket: Cross Licenses, Patent Pools, and Standard Setting, in i Innovation Policy And the Economy irg (Adam B. Jaffe et al. eds., NBER 2000).

Stephen Shmanske, News as a Public Good: Cooperative Ownership, Price Commitments, and the Success of the Associated Press, 60 Business History Rev. 55 (1986).

Henry E. Smith, Semicommon Property Rights and Scattering in the Open Fields, 29 J. LegaL STUdies i3i (2000).

Ruth Maria Stock, Pedro Oliveira, \& Eric A. Von Hippel, Impacts of Hedonic and Utilitarian User Motives on the Innovativeness of User-Developed Solutions (MIT Sloan School of Management Working Paper 2013), http://ssrn.com/abstract $=2260436$.

Katherine J. Strandburg, Curiosity-Driven Research and University Technology Transfer, in 16 University Entrepreneurship and Technology Transfer: Process, Design, and Intellectual Property 93 (JAi Press 2005).

Katherine J. Strandburg et al., Law and the Science of Networks: An Overview and an Application to the "Patent Explosion," 2I Berkeley TeCh. L.J. I293 (2006). 
Katherine J. Strandburg, User Innovator Community Norms: At the Boundary Between Academic and Industry Research, 77 Fordham L. Rev. 2237 (2009).

Katherine J. Strandburg, Norms and the Sharing of Research Materials and Tacit Knowledge, in Working Within the Boundaries of Intellectual Property (Rochelle C. Dreyfuss et al. eds., Oxford University Press 2010).

Jean Tirole \& Josh Lerner, Some Simple Economics of Open Source, 50 J. Industrial Economics 197 (2002)

Rebecca Tushnet, Economies of Desire: Fair Use and Marketplace Assumptions, 5I William \& MARY L. ReV. 513 (2009).

W. Kip Viscusi et al., Economics of Regulation and Antitrust (4th ed. MiT Press 2005).

Eric von Hippel, Democratizing Innovation (MIT Press 2005).

Eric von Hippel \& Harold Demonaco, Market Failure in Diffusion of User Innovations: The Case of "Off-Label" Innovations by Medical Clinicians, (MIT Sloan School of Management Working Paper 2013), http://ssrn.com/abstract $=2275562$.

John P. Walsh et al., Where Excludability Matters: Material Versus Intellectual Property in Academic Biomedical Research, 36 ReseARCH Policy II 44 (2007).

Joel West, Seeking Open Infrastructure: Contrasting Open Standards, Open Source and Open Innovation, I2 FIRST MONDAY no. 6 (June 4, 2007), http://firstmonday.org/htbin/cgiwrap/ bin/ojs/index.php/fm/article/view/1913/1795.

Diane Leenheer Zimmerman, Copyrights as Incentives: Did We Just Imagine That?, I2 Theoretical Ineuiries L. 29 (20II). 